مجلة جامعة أم درمان الاسلامية

\title{
https://journal.oiu.edu.sd/index.php/oiuj
}

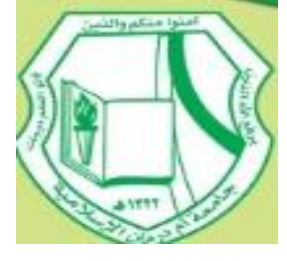

ISSN: 5361-1858

\section{دور المحاسبة عن التنمية المستدامة في تحسين المحتوى الإعلامي للتقارير المالية}

The Role of Sustainable Development Accounting in Improving the Informational

\section{Content of Financial Reports}

د. دآدم الطيب حماد حامد"

* الأستاذ المساعد كلية الوسيلة للعوم والتكنولوجيا - السودان

| (المستخلص

هدفت الدراسـة إلى قيـاس العلاقـة بين أبعـاد المحاسبة عن التتميـة المسـتدامة وتحسين المحتوي الإعلامي للتقارير المالية بشركات المساهمة السودانية، حيث تمثلت مشكلة الدراسة في أن التقارير المالية التقليديـة لا تهنت بالبيانات الخاصـة بأبعاد التتميـة المستدامة، مدـا قد يؤثر في ترشيد القرارات الاستثمارية وانعكاس ذلك على المحتوى الإعلامي للتقارير المالية لثركات المساهمة بسوق الخرطوم للأوراق المالية، توصلت الدراسـة إلى عدة نتائج أهمها سـاعد الإفصـاح عن البيئة الصحية للعاملين بالثـركة في تحسين المحتوي الإعلامي للتقارير المالية، ساعد الاهتمام بتوفير أجهزة لتقليل النلوث البيئي في تحسين المحتوي الإعلامسي للتقـارير الماليـة، أوصـت الدراسـة بضــرورة الإفصـاح عـن المعلومـات المتعلقـة بالبعـــ البيأسي والاجتماعي بالتقارير المالية، ضرورة لالتزام بالبعد الاقتصادي لمحاسبة التتمية المستدامة لتحسين المحتوي الإعلامي للتقارير المالية. الكلمات المفتاحية: المحاسبة عن التتمية المستدامة -البعد البيئي - البعد الاجتماعي - البعد الاقتصادي المحتوى الإعلامي للتقارير المالية. 


\section{Abstract}

The study aimed to measure the relationship between the dimensions of accounting for sustainable development and improve the media content of the financial reports in the Sudanese joint-stock companies, as the problem of the study was that the traditional financial reports do not care about the data on the dimensions of sustainable development, which may affect the rationalization of investment decisions and its reflection on the media content of the reports The study reached several results, the most important of which was the disclosure of the healthy environment for the company's employees in improving the media content of the financial reports. The interest in providing devices to reduce environmental pollution has helped improve the media content of financial reports. The study recommended the necessity of disclosing information related to the environmental and social dimension of financial reports. A commitment to the economic dimension of sustainable development accounting is necessary to improve the media content of financial reports.

Key words: accounting for sustainable development - the environmental dimension - the social dimension - the economic dimension - the media content of financial reports. 
تعتبر محاسبة التتميـة المستخامة من المفاهيم التي نالت اهتمامـا كثيرا من جميع النواحي البيئية والاجتماعية والاقتصادية والمحاسبية، كما أن المحاسبة لم تعد عملية مسك للدفاتر فقط، إنما تعددت وظائفها ومهامها فهناك محاسبة التكلفة البيئية ومحاسبة المسؤولية الاجتماعيـة ومحاسبة الاستدامة ومـن الناحية المحاسبية، من جهة أخري تعد القوائم والتقارير المالية أهم المصادر التي تعتمد عليها الأطراف ذات العلاقة بالثركة للحصول علي المعلومات التي يحتاجونها في اتخاذ قراراتهمهومع التغير في بيئة الأعمال أصبح هنالك اتفاق علي أن التقارير الماليـة أصبحت لا تعبر بصورة كافيـة الأبعاد في الوقت الحاضر ،ظهرت الحاجـة إلـي الإفصـاح عن معلومـات غير ماليـة تشـل قضـايا بيئيـة واجتماعيـة واقتصـادية وأن المحتوي الإعلامي للتقارير المالية في ظل هذه المتغيرات سيصبح لـه دور فعال في توجيه سلوك كافه القطاعات الاقتصادية وكذلك المستخدمين من درجة الثفافية والمصداقية للمعلومات التي تحتوي عليها التقارير المالية، بعد أن عجزت بعض المنشـآت في توفير البيانـات الكافيـة للمسـتخدمين وإعطـائهم المعلومـات المرتبطـة بمصادر تمويل الاستثمارات الضخمة داخل المنشأة. مشكلة الدراسة: حيث تمثلت مشكلة الدراسة في أن التقارير المالية التقليدية لا تهتم بالبيانات الخاصـة بأبعاد التتمية المستدامة، مما قد يؤثز في ترشيد القرارات الاستثمارية وانعكاس ذلك على المحتوى الإعلامي للتقارير المالية لثركات المساهمة بسوق الخرطوم للأوراق المالية.يمكن صياغة مشكلة الدراسة في الآتي: 1. هل هنالك علاقة بين الاهتمام بالبعد البيئي لمحاسبة التنمية المستدامة وتحسين المحتوي الإعلامي للتقارير المالية المنشورة بشركات المساهمة بسوق الخرطوم للأوراق المالية؟ 2. هـل هناللك علاقـة بين الاهتمـام بالبعد الاجتمـاعي لمحاسبة التتميـة المستـامة وتحسـين المحتوي الإعلامي التقارير المالية؟ 3. هـل هنالك علاقـة بين الاهتمـام بالبعد الاقتصـادي لمحاسبة التتميـة المستـامة وتحسين المستوي

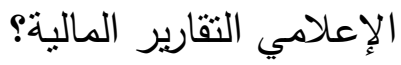


أهمية الدراسة: تتمنل أهمية الدراسة في الآتي:

يعد البحث إضافة علمية للمكتبات الأكاديمية حيث يقام مادة علمية للباحثين عما يتعلق بدور أبعاد المحاسبة عن التتمية المستدامة في تحسين محتوى الإعلامي للتقارير المالية. أهداف الاراسة: تتمنل أهداف الدراسة في الآتي:

1. التعرف على الإطار النظري للمحاسبة عن التتمية المستدامة.

2. التعرف على العلاقة بين البعد البيئي لمحاسبة التتمية المستدامة وتحسين المحتوي الإعلامي للتقارير المالية بشركات المساهمة السودانية.

3. التعـرف على العلاقـة بين البعد الاجتمـاعي للمحاسبة لمحاسبة التتميـة المستـامة وتحسين المحتوي

$$
\text { الإعلامي للتقارير المالية بشركات المساهمة السودانية. }
$$

4. التعرف على العلاقة بين البعد الاقتصـادي لمحاسبة التتميـة المستدامة وتحسين المحتوي الإعلامسي للتقارير المالية. فرضيات الاراسة: تتمنل فرضيات الدراسة في الآتي:

1. توجد علاقة ذات دلالة إحصائية بين الاهتمام بالبعد البيئي لمحاسبة التتمية المستدامة وتحسين المحتوي الإعلامي للتقارير المالية بشركات المساهمة السودانية 2. توجد علاقة ذات دلالة إحصائية بين الاهتمام بالبعد الاجتماعي للمحاسبة لمحاسبة التتمية المستدامة وتحسين المحتوي الإعلامي للتقارير المالية بشركات المساهمة السودانية. 3. توجد علاقة ذات دلالة إحصائية بين الاهتمام بالبعد الاقتصادي لدحاسبة التتمية المستدامة وتحسين المحتوي الإعلامي للنقارير المالية. منهج الدراسة: اتبعت الدراسة المناهج الآتية: اعتمد الباحث علي المنهج الاستقرائي، والمنهج الاسنتباطي، والمنهج التاريخي،والمنهج التحليلي الوصفي لجمع البيانات والمعلومات وتحليلها. 


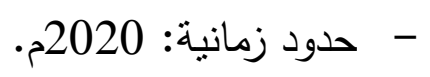

- - حدود مكانية: الخرطوم - سوق الخرطوم للأوراق المالي (شركات المساهمة العام).

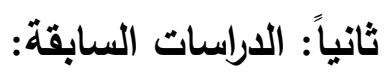

دراسـة عباس، (2017): تمنلت مشكلة البحث في عدم اهتمام العديد من المنشآت الصناعية السودانية بالقياس والإفصاح عن أنشطة محاسبة التتمية المستدامة (البيئية، الاجتماعية، الاقتصادية) على الرغم من دورها المهم في تحقيق الميزة التتافسية لها، هدفت الدراسة إلى التعرف على نظام محاسبة التتمية المستدامة من حيث المفهوم والهدف والطرق، والتعرف على التحديات التي تواجه قياس الأنشطة البيئية والاجتماعية لمحاسبة التتمية المستدامة، ولتحقيق أهداف البحث وحلا لمشكلته وتوصلت الدراسة إلى عدة نتائج منها التزام المنشـأة بقياس تكاليف أنشطتها البيئيـة والاجتماعيـة يجنبها دفع الغرامـات والجزاءات للأطراف الخارجيـة المتضررة مما يؤدي إلى تخفيض التكلفة مقارنة بالمنافسين. تختلف دراسة الباحث عن هذه الدراسة في أنها تتاولت محاسبة التتمية المستدامة ودورها في تحقيق الميزة التتافسية، بينما اختلفت عنها هذه الدراسة في تتاولها قرارات الاستثمار من المساهمين من البنوك في نيجريا. دراسـة: هيثم (2017م): تمثلت مشكلة الدراسـة في يعتبر إصدار المعيار الدولي للتقارير المالية الخاص بالمنشـآت الصـغيرة ومتوسطة الحجم خطوة كبيرة نحو إتمـام دور مجلس معـيير المحاسبة الدوليـة على تلى المستوى الدولي وذللك للقياس والإفصاح المحاسبي لتلاك المنشآت، هدفت الدراسة إلى التعرف على المنشآت الصغير ومتوسطة الحجم SMEs، توصلت الدراسة إلى عدة نتائج أهمها: يتضح من التحليل الإحصائي لآراء المستقصي منهم أن تطبيق المعيار الدولي للتقارير المالية للمنشآت الصغيرة ومنوسطة الحجم في البيئة المصرية سوف يؤدي إلى تحسين جودة التقارير والقوائم المالية. تختلف دراسـة الباحث عن هذه الدراسـة في أنها تتاولت دور المحاسبة عن التتمية المستدامة في تحسين محتوى الإعلامسي للتقارير المالية وترشيد قرارات الاستثمار، بينما اختلفت عنها هذه الدراسـة في تتاولها تحسين جودة المحتوى الإخباري للقوائم الماليـة للمشـروعات الصـغيرة ومتوسطة الحجم في ضـوء المعيار الدولي للتقارير المالية. 
دراسـة: وليـ(2018م): تمثلت مشكلة الدراسـة في أنه لم تعد مشـاكل التتميـة المستدامة مشكلة محلية أو إقليمية إنما هي مشكلة دولية وأن الاهتمام بقضايا الاستدامة في جوانبها الثلاثة الاقتصادية والاجتماعية والبيئية أصبحت تمثل رأس الرمح في تأكيد رفاهية ورقي المجتمعات أو عدم اهتمامها بالنواحي الاقتصادية والاجتماعيـة والبيئيـة، هـفتت الدراسـة إلى تحليـل ومناقثــة وجهات النظـر المؤيدة والمعارضــة بالمنشـآت المصرفية لعملية التقرير عن الأداء البيئي والاجتماعي، نوصلت الدراسة إلى عدة نتائج أهمها: إفصاح تقرير الإستدامة عن مؤشرات الأداء الاقتصادي قلل من مخاطر قرارات الدصارف الاستثمارية، تقرير الإستدامة عن الجوانب الإقتصادية ساهم في جودة الإفصاح عن تقرير الإسندامة الثناثي، تقرير الإستدامة الإجتماعي زاد من وعي وإدراك وثقة المستخدمين في تقارير الإستدامة وقراراتهم تجاه أسهم المصارف. تختلف دراسـة الباحث عن هذه الدراسـة في أنها تتاولت دور المحاسبة عن التتمية المستدامة في تحسين محتوى الإعلامي للتقارير المالية وترشيد قرارات الاستثمار ، بينما اختلفت عنها هذه الدراسـة في تتاولها خصائص الوحدات الاقتصادية في جودة الأرباح المحاسبية لترشيد قرارات الاستثمار في سوق الأوراق

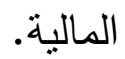

دراسـة: أحمد(2018م): تمثلت مشكلة الدراسة في أصبح الإفصـاح عن المعلومات والبيانات الاقتصادية والبيئية والاجتماعيـة الطريقة التي تلجأ إليه المنظمات التي تهدف إلى الاستمرار بالدرجة الأولى وعكس صورة إيجابية عن أدائها لدى الأفراد المتعاملين معها، ويعتبر القطاع المصرفي من المؤسسات المالية التي تسعى جاهدة إلى احتلال مكانة مرموقة في المجتمع تؤهلها للحفاظ على استمرارها رغم ما قد تتعرض لله من حالات تعثر وفثنل مالي، هدفت الدراسة إلى التعرف على مسنتى الإفصاح عن أبعاد الاستخامة في البنوك في بورصة عمان، توصلت الدراسة إلى عدة نتائج أهمها: وجود مستوى منخفض لإفصاح البنوك المدرجة في بورصة عمان عن أبعاد التتمية المستدامة، وجود مستوى منوسط عن إفصاح البنوك المدرجة في بورصة عمان عن البعد الاقتصادي.

تختلف دراسـة الباحث عن هذه الدراسـة في أنها تتاولت دور المحاسبة عن التتمية المستدامة في تحسين محتوى الإعلامسي للتقارير المالية وترشبد قرارات الاستثمار، بينما اختلفت عنها هذه الدراسـة في تتاولها مستوى الإفصاح عن أبعاد الاستدامة لدى القطاع المصرف الأردني. 
دراسـة: محمد (2020م): تمنلت مشكلة الدراسـة في غياب الطرق الموحدة لإعداد ونشر التقارير المالية إلكترونياً مما أدى إلى ظهور حالة من الفوضى في النشر الإلكتروني وأصبح المستخدمون غير قادرين على تحقيق الاستفادة الكاملة من هذه المعلومات المالية، مما أدى ازدياد المطالبات العالمية بوجود طريقة معيارية لإعداد ونشر التقارير المالية إكترونياً لذلك تتلخص مشكلة الدراسة في مدى تأثنر تطبيق لغة تقارير الأعمال الموسعة (XBRL) في تحسين المحتوى الإعلامي للتقارير المالية، هدفت الدراسة إلى توضيح أثر استخدام لغة تقارير الأعمال الموسعة (XBRL) في تحسين جودة المحتوى الإعلامي للتقارير المالية. توصلت الدراسة

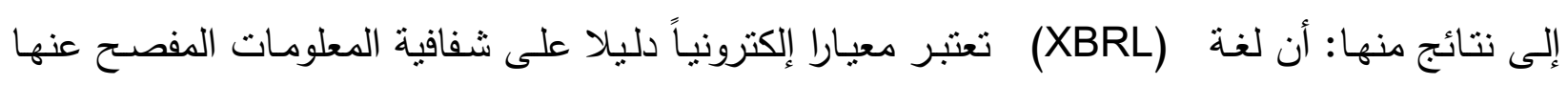
بالمصارف السودانية، عملت (XBRL) على تخفيض تكاليف إعداد التقارير المالية بالمصارف السودانية. تختلف دراسـة الباحث عن هذه الدراسـة في أنها تناولت دور المحاسبة عن التتمية المستدامة في تحسين محتوى الإعلامسي للتقارير المالية وترشيد قرارات الاستثمار، بينمـا اختلفت عنها هذه الدراسـة في تتاولها تقارير الأعمال الموسعة وأثرها في المحتوى الإعلامي للتقارير المالية. ثالثاً: الإطار النظري للاراسة: 1/ مفهوم محاسبة التتمية المستدامة: هنالك العديد من تعريفات محاسبة التتمية المستدامة منها: فقد عرفت على أنها تتبع الأنشطة والموارد البيئية واستخدام المعلومات في اتخاذ القرارات البيئية بهدف تحديد وإزالــة الآثـار السـلبية للأنشـطة والـنظم (عصـام، 2008، ص 174)، وعرفت أيضـاً أنهـا: إدارة الأداء البيئسي والاقتصادي من خلال تهيئة وتطوير نظم محاسبية ملائمة تتعلق بالبيئة وتطبيقاتها(هادي، 2006،ص8) وعرفت أيضاً بأنها نظام للمعلومات يختص بوظيفتي قياس الأداء البيئي والاجتماعي والاقتصادي للمنشأة والتقرير عن نتائج هذا القياس بما يكفل تقييم إسهاماتها في تحقيق التتمية المستدامة (محمد، 2013، ص38). مما تقدم يرى الباحث أن محاسبة التتمية المستدامة هي نظام للمعلومات يختص بقياس التكاليف الخاصـة بالأنشطة البيئية والاجتماعية والاقتصادية للمنشأة والتقرير عن هذه الأنشطة. 2/ أهميـة محاسبة التنميـة المستدامة: ومن ناحية أخرى توفر محاسبة الاستدامة معلومات للمستخدمين الداخليين والمتمتلين في إدارة المنشاة لاتخاذ القرارات ومساعدتها في تحقيق أهداف الاستخامة متعددة الأبعاد، وباعتبار الاستدامة تثكل جزءا أساسيا في إستراتيجية الثركات، وتساعد محاسبة الاستدامة المنظمات في تضمين قضايا الاستدامة داخل التخطيط الاستراتيجي للمنشاة وذلك من خلال ما توفره من معلومات مالية 
وغير مالية، هذا بالإضافة إلى دورها في تحقيق المساعلة والثفافية والحوكمة وإدارة الدخاطر ، وإيجاد مصادر

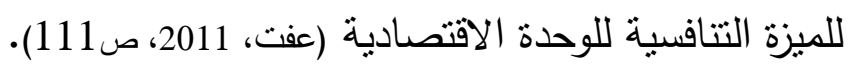
3/ أهداف محاسبة التنمية المستدامة: الهدف الأساسي هو قياس أداء المنشأة نحو هدف الاستدامة من وجهة النظر الاقتصادية والاجتماعية والبيئية وذلك لتحقيق المساعلة والثفافية والإفصاح عن نشاط المنشأة وتوفير معلومات مفيدة لأغراض اتخاذ القرارات الداخلية والخارجية ويمكن التمييز بين المستخدمين الداخليين لمعلومـات الاستـامة وبين المسـتخدمين الخـارجيين لهذه المعلومـات، وتوفر محاسبة الاستـامة معلومـات

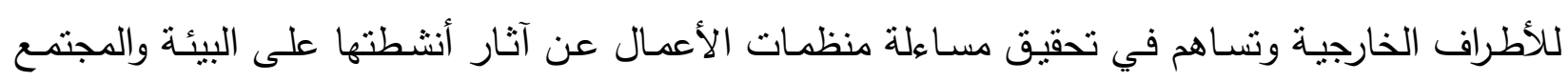
بصفه عامة (رحاب، 2016، ص20).

مدا تقدم يتضـح للباحث أن هدف محاسبة الاستدامة يتمحور حول العمل على عرض تفاصيل النشـاط الاقتصادي والاجتماعي والبيئي لمنشأة الأعمال والعمل على تمكين هذه المنشأة من التقرير عن هذه الأنشطة بصورة واضحة وشفافة وتمكن المجتمع من معرفة طبيعة هذه الأنشطة حتى يتمكن من ممارسة دوره الرقابي على هذه المنشآت.

5/أبعاد التنمية المستدامة: بناءً على ما تقدم من تعريفات للتتمية المستدامة تبين أنها لا تركز فقط على الجانب البيئي بل تشمل أيضا على عدة جوانب أخرى أساسية تحمل في طياتها مجموعة من القضايا التي تعبر عن مؤشرات يمكن من خلالها قياس المستوى الذي وصلت إليه التتميـة المستدامة وعليه فإن هذه

$$
\text { الأبعاد تتمنل في: (راشي، 2011، ص22): }
$$

أ. البعد الاقتصـادي للتنميـة المستدامة:بستتد هذا البعد أساسـاً على المبدأ الذي يقضـي بزيـادة رفاهيـة المجتمع إلى أقصى حد ممكن نزامنا مع إدارة استغلال الموارد الطبيعية بطريقة عقلانية ورشيدة تحافظ على توازن البيئة واستمراريتها. ب. البعد الاجتمـاعي للتنميـة المستدامة: يركز البعد الاجتماعي للتتمية المستدامة على أن الإنسـان هو محورها الأساسي وجوهرها باعتباره وسيلة وهدف في أن واحد، وعليه يهتم هذا البعد بالعدالة الاجتماعية وتحقيق المساواة ومكافحة الفقر وتوزيع الموارد وتقديم وتحسين مستوى الخدمات الاجتماعية الرئيسية إلى كل المحتاجين لها والسعي المتواصل في تحقيق استقرار النمو الديمغرافي حتى لا تكون هنالك ضـوط على الموارد الطبيعية والعمل على وقف التروح الريفي، بالإضـافة إلى الأخذ بعين الاعتبار 
أهمية مشاركة الثعوب في اتخاذ القرارات والحصول على المعلومات التي نؤثز على حياتهم بشفافية

$$
\text { ودقة (جميل، 1997، ص4). }
$$

ج. البعد البيئي: يقضي هذا البعد على أن البيئية هي محور الاهنمام وأنه من أجل تحقيق تتمية مستدامة يجب الحفاظ على هذه البيئية وذلك من خلال: - - منع تجريف التربة. - وخفض استعمال المبيدات والحد من تدمير الغطاء النباتي والمصايد. مما تقدم يصل الباحث إلى أن هذه الأبعاد هي عبارة عن منظومة واحدة فإذا تم فقدان أحد هذه عناصرها أفقدت شكلها الطبيعي، لذلك لابد أن تقوم الدولة بإصدار قانونين تمنع قيام أي مشروعات لا تلتزم بأخذ هذه

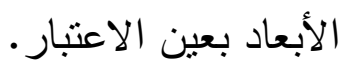

6/ القياس المحاسبي لمحاسبة التنمية المستدامة: يجد المطالع على أدبيات المحاسبة البيئية والاجتماعية أنه يمكن التمبيز بين مدخلين للقياس على النحو

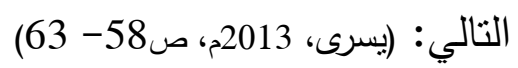
أ/مـذخل القياس ذو المضمون الواحد: يقوم مدخل القياس الكمي ذو المضمون الواحد بصفه عامـة على قياس الأشياء والظواهر كمياً بمعيار موحد يعكس خاصية مشتركة بينها، بحيث يمكن أن تتوافر للمعلومات الناتجة عن قباس هذه الأثياء والظواهر خاصية التجميع الرياضي على مستوى جميع العناصر المكونة لها، وفي مجال القياس البيئي والاجتماعي يفرق بين اتجاهين بخصوص المعيار الموحد الذي يستخدم في قياس

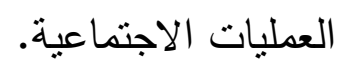

- الاتجاه الأول: القياس باستخدام وحدة المنفعة الاجتماعية: يدور منطق هذا الاتجاه حول ما ينبغي أن يكون عليه القياس الاجتماعي. - الاتجاه الثاني: القياس باستخدام وحدة النقد: يعتمد القياس في المحاسبة المالية على أسعار التبادل، وفيما يختص بالمحاسبة عن التتمية المستدامة سبق الاتفاق على أنه غالباً ما تكون هذه الأسعار

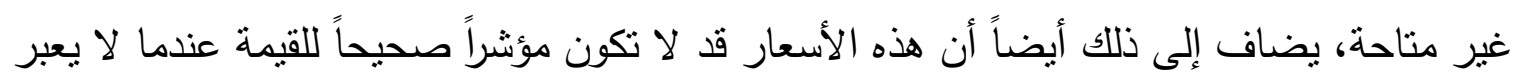
السعر عن المنفعة التي تحققها السلعة أو الذدمة. هذا وللتغلب على صعوبة قياس العمليات البيئية 
والاجتماعية في صورة نقدية اقترح Estes تقدير قيمة هذه العمليات استتاداً إلى بعض طرق التقدير غير المباشر منها: I. طريقة التقييم البديل. II. طريقة الاستقصاء.

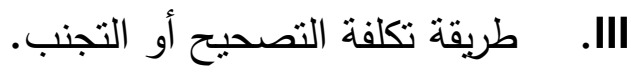
وفيها يتم تقدير الأضرار على أساس المبالغ اللازمة لتصحيح الضرر أو المبالغ اللازمة للمعدات والأجهزة الضرورية لتجنب الضرر.

ب/ مدخل القياس متعدد الأبعاد: ويستتد استخدام هذا المدخل في مجال القياس البيئي على الطبيعة المميزة للعمليات البيئية موضوع القياس (احمد، 2006م، ص452). يقوم مدخل القياس متعدد الأبعاد علي قياس الأشياء والظواهر بأساليب قياس مختلفة توفر معلومات تعكس تباين وتعدد خصائص الأشياء والظواهر موضوع القياس وذلك دون التقبد بأسلوب قياس معين أو بنظام قياس محدد أو الاعتماد على مقياس وحيد. ويستتد استخدام المدخل في مجال قياس التتمية المستدامة في الطبيعة المميزة للعمليات بتعدد جوانبها وتباين أبعاد نأثيراتها، فإن مدخل القياس الملائم الذي ينبغي الاعتماد عليه في قياس هذه الطبيعة يجب أن يضفي دلالة أكثر وضوحاً لتأثير العمليات البيئية والاجتماعية عما تضفيه المعلومات ذات الطبيعة المالية فالمعلومات عن مقدار التخفيض في معدلات التلوث أو عدد العاملين الذين استفادوا من برامج التدريب أو نسبة النقص في الحوادث نتيجة تطوير تصميم المنتج أو توصيف مسـاهمة المشروع في تحقيق بعض الأهداف القومية قد تكون أحياناً لها دلالة بيئية واجتماعية أفضل من المعلومات المتولدة عن استخدام مدخل القياس النقدي (محمد، 2011م، ص 220). مدا تقدم يرى الباحث أن هنالك صعوبة في قياس التكاليف البيائية والاجتماعية نظراً لطبيعة أنواع هذه التكاليف، وهذه الصعوبة تتبلور في اختلاف وجهات النظر بين الاقتصاديين والمحاسبيين، فالمحاسبون يرون التكاليف الاجتماعية أو البيئية هي التكاليف التي تتفقها المنشأة ولا يتطلبها نشاطها الاقتصادي. 7//الإفصاح المحاسبي عن أبعاد محاسبة التنمية المستدامة: • البعـد الاقتصـادي: الإفصـاح عن معلومـات القيمـة الاقتصـادية الموزعـة والمتبقيـة.الغرامات والجزاءات

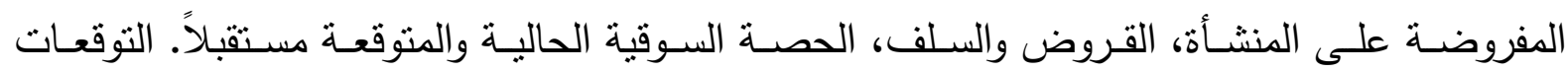


المستقبلية للمبيعات والأرباح والخسائر للعام المقبل، منع الاحتكار وعدم الإضرار بالمستهلكين، احترام قواعد المنافسة وعدم الإضرار بالمنافسين، إدارة المخاطر التي تواجه الثركة. * البعد الاجتماعي: الإفصاح عن مدى المساهمة في دعم المشروعات الصغيرة، مدى المساهمة في حل بعض المشاكل الاجتماعية للإسكان، مدى المساهمة في توفير فرص عمل لمعالجة البطالة، مدى المساهمة

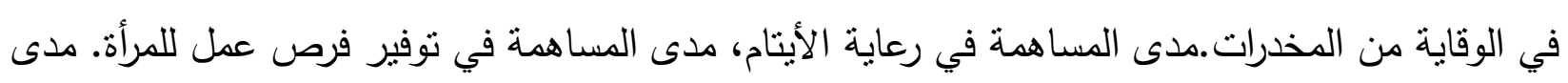
المساهمة في الحد من الاختناقات المرورية، الحوافز المقدمة للموظفين لتطوير مهاراتهم وإكمال تعليمهم. * البعد البيئي:الإفصاح عن حجم استهلاك الموارد الطبيعية، إجمالي المياه المعاد معالجتها .جهود تحسين استخدامات الطاقة.مدى المساهمة في اكتشاف مصادر جديدة للطاقة والمواد الخام، مدى مساهمتها في رفع الوعي البيئي.مدى المساهمة في تشجيع لأبحاث منع النلوث والضوضلاء وتجميل البيئة.كيفية التخلص من 8/المخلفات الضارة بالبيئة كإعادة التصنيع (التدوير).

يقصد بالمحتوى الإعلامي للتقارير المالية "قيمة مـا يحتويـه التقرير المالي من معلومات اقتصـادية ذات علاقة بالشركة، مثل: القرارات التي يتخذها المستثمرون بشأن توظيف أموالهم أو قرارات المقرضين بشأن منحهم التسهيلات المصرفية"(Brown, 2005)، وخلص آخر إلى أنها " تأثنير حدث أو معلومات معينة كالإعلان عن توزيعات الأرباح على أسعار الأسهم المتداولة بالسوق، وأن البنود التي تتشر في القوائم المالية للشركة تعبر عن خصائصها في وضع معين" (طلعت وأخرون، 2004م، صأسم).

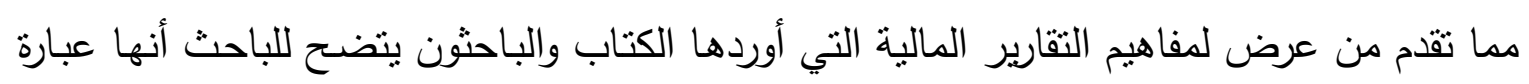
عن مخرجات النظام المحاسبي الموجود بالثـركة، تهنت بعرض العمليات والأحداث ذات الطبيعـة الماليـة بصورة واضحة ودقيقة وتوصيلها للمستخدمين بغرض تلبية احتياجاتهم وتزويدهم بالمعلومات اللازمة لاتخاذ القرارات بصورة مناسبة. 9/ أهمية المحتوى الإعلامي للتقارير المالية: تزايد الاهتمام بالوظيفة الإعلامية للمحاسبة مع ظهور نظريات الاتصـالات والاستثمارات الحديثة، وما ترتب عليه من زيادة الطلب على المعلومات المحاسبية من جانب مستخدمي المعلومات المحاسبية، وكذلك من جانب الإدارة نتيجة الاتجاه إلى المنهج العلمي لاتخاذ القرارات، إن الاهتمام العالمي بالوظيفة 
المحاسبية لم يعطيها تأكيداً حول مدى فاعلية المعلومات المحاسبية ومدى ملاءمتها للاستخدامات المتعددة والنمـاذج القراريـة المتباينـة سـواء كانـت تتـغيلية أو اسـتنمارية أو تمويليـة، خاصــة وأن نطــاق الاهتمـام بالمعلومات المحاسبية لم يعد قاصراً على فئة معينة في ظل ما بعيشهه عالم الأعمال اليوم من متغيرات

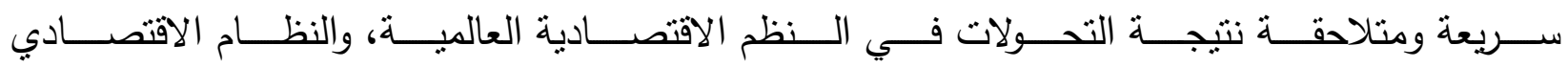
المحلي(عبدالرحم،1994م،ص335)، إن المحتوى الإعلامي في ظل المتغيرات العالمية والمحلية سيصبح له دور فعال في توجيه سلوك كافة القطاعات الاقتصادية، وكذلك سلوك المستخدمين من خلال درجة المصداقية والثفافية للمعلومـات المحاسبية والتي تتمثل في المحتوى الإعلامسي لوسيلة الاتصـال بين الثـركة والبيئة المحيطة بها والتي تعمل من خلالها (مرعي، 1979م، ص 27)، إن البعد الإعلامي المحاسبي لم يلقى نفس القدر من الاهتمام في معظم الدول النامية، حيث أن الاهتمام بعملية القياس المحاسبي، وغياب دور المنظمات المهنية بالإضافة إلى التنخل الحكومي للإعلام المحاسبي حد من الاهتمام المتزايد بالمحتوى الإعلامي، إلا أنه في فترة أواخر الثمانينات وبداية التسعينات برز اهتمام المنظمات المهنية على الصعيد المحلي بموضوع

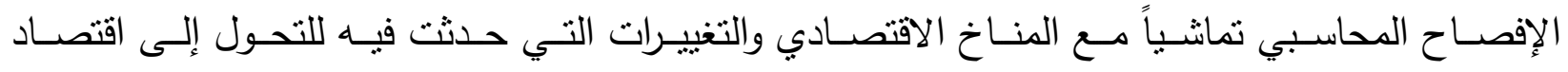
السوق(عبدالرحمن، 1994م،صـ338).

مما تقدم يتضح للباحث من عرض لأهمية التقارير المالية أن أهيتها تتمثل في المساهمة في عكس الحقائق المالية ونتائج العمليات والأحداث بالثركة، إظهار المعلومات اللازمة التي تساعد المستخدمين في اتخاذ قراراتهم الاقتصادية بشكل سليم. 10/ أهداف المحتوى الإعلامي للتقارير المالية: أ. تقويم أداء الشركات ومدى تحقيقها لأهدافها وذلك على مستوى الإدارة أو الغير. ب. تقويم الأداء للإدارة وكفاءتها والتحقق من إمكانيات وخبرات المديرين. ج. نقدير درجة السيولة التي تتمتع بها الثركة حالياً ومستقبلاً واحتباجاتها للأموال وقدرتها على الاقتراض. د. اشتمال التقارير المالية المنشورة على معلومات مفيدة عن المخاطرة لمتخذي القرارات الاقتصادية الرشيدة،

$$
\text { وذللك من خلال (day, 1986, p } 301 \text { - (da): }
$$

- - توفير معلومات تفيد مستخدمي التقارير المالية التي تبين توقعات الإدارة المستقبلية. - تقديم معلومات عن الإنفاق الاستثماري المستقبلي. 
- ج. معلومات عن الأسس التي أعدت عليها التقارير المالية. - - د. دملومات عن التدفقات النقدية. - - هـ معلومات تفيد في تقويم الأوراق المالية للشركات التي تطرح أوراقها في السوق.

يضيف الباحث الأهداف التالية للتقارير المالية: - تزوبد المستخدمين بالمعلومات الكافية التي تمكنهم من اتخاذ القرارات المناسبة. - توفير المعلومات المتعلقة بالأداء المالي للثركة وكيفية تسييرها لكافة الأنشطة المختلفة. 11 أنواع المحتوى الإعلامي للتقاريز المالية: أ. المحتوى الإعلامي لملائمة القيمة: يعتبر المحتوى الإعلامي لملائمة القيمة من أنواع محتوى التقارير

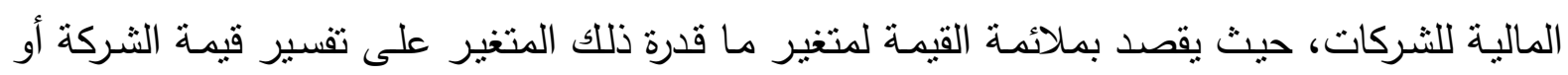
أسعار أسهـها بشكل دقيق، ويقصد بملائمسة القيمة إظهار القيمة الاقتصادية للمعلومات التي تتشرها

$$
\text { الشركة ضمن تقاريرها المالية (محمد، عباس، 2003م، ص 18). }
$$

ب. المحتوى الإعلامي للأرياح المحاسبية: يمنل المحتوى الإعلامي للأرباح المحاسبية التي تحققها الثركة أحد أهم أنواع المحتوى الإعلامي للتقارير المالية، حيث إن المحتوى الإعلامي للأرباح المحاسبية يوضح بعض المقاييس المحاسبية المبنية على أداء الربح المحاسبي المنشورة ضـن التقارير الماليـة للثـركة والمتمتلة في معدل العائد على حقوق الملكية، والذي يعبر عن العلاقة بين الأموال المستثمرة من قبل مالكي الثركة والعوائد المستمدة منها. ج. المحتوى الإعلامي للتدفق النقدي الحر: يعد المحتوى الإعلامي للندفق النقدي الحر أحد أنواع المحتوى الإعلامي للتقارير المالية، حيث يقصد به المبلغ النقدي المتبقي من عمليات الثركة بعد استخدام النقدية في الاستثمارات الجديدة، أي أنه النقدية المتاحة فعلياً للافع لحملة الأوراق المالية(Beneda,2003,p247). د. المحتوى الإعلامي للتدفقات النقدية: يعتبر المحتوى الإعلامي للمعلومات الواردة بقائمة التدفقات النقدية من أنواع المحتوى الإعلامي لتقارير الثركات، حيث يستتد مؤيدو قائمة التدفقات النقدية على أهميتها في توفير قياسات محاسبية ملائمة لاتخاذ القرارات الاقتصادية الرشيدة. 
هـ. المحتوى الإعلامسي لتوزيعات الأربـاح: إن من أنواع المحتوى الإعلامسي للتقارير المالية للثركات هو المحتوى الإعلامي لتوزيعات الأرباح التي تحققها الثركة، حيث أن تلك الأرباح تتتج من خلال زيادة مجموع إيرادات الثركة خلال السنة المالية عن مجموع المصاريف والاستهلاكات خلال نفس السنة.

\section{2 محاسبة التمية المستدامة وتحسين المحتوى الإعلامي للتقارير المالية:} إن التطور الاقتصـادي والمنافسـة الثديدة قد جعل الوحدات الاقتصـادية تهمل الجانب الاجتماعي كخدمة العاملين والبيئة والمجتمع وتركز على الجانب الاقتصـادي وتحقيق الربحية فقطفقد لقي موضوع الإفصـاح المحاسبي عن أبعاد التتمية المستدامة الاهتمام من جانب بعض الجهات الأكاديمية والمهنية والتي أصدرت عددا من التوصيات والآراء بخصوص المعلومات التي يتعين الإفصساح عنها في القوائم المالية من حيث نوعيتها ومدى منفعتها للمستخدمين وكنلك ظهرت دراسات ميدانية لقياس الأهمية النسبية لبعض المعلومات الخاصة بالمسؤولية الاجتماعية المالية منها وغير المالية في القوائم المالية الداخلية أم الخارجية، حيث يتخ الإفصاح عن أبعاد التتمية المستدامة معبرة عنها بوحدة النقد ضمن قائمة الدخل وقائمة المركز المالي بجانب المعلومات المالية، حيث يتم إظهار جميع المبالغ التي أنفقت على كل نشاط (دجلة ، 2014م، ص 230). عليه يتضـح للباحث أن الإفصـاح عن محاسبة التتمية المستدامة يسـاهم في تحسين المحتوى الإعلامسي للتقارير المالية من خلال الأبعاد التالية:

\section{أ. الإفصاح عن البعد الاجتماعي لمحاسبة التنمية المستدامة من خلال:}

- الإفصاح عن مشاريع تتمية المجتمع بالتقارير المالية يؤدي إلى تحسين المحتوي الإعلامي للتقارير

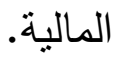

- الاهتمام بنتجيع العاملين على تقديم أفكار جديدة يساهم في تحسين المحتوي الإعلامي للتقارير المالية للمنشآت الصناعية.

- الإفصاح عن مدى اهتمام الثركات بتعويض العاملين مقابل إضرار ببيئة العمل يؤدي إلي تحسين المحتوي الإعلامي للتقارير المالية. 
- الاهتمام بتعليم العاملين بالثركة يساهم في تحسين المحتوي الإعلامي للتقارير المالية. - - العمل على تحقيق الرفاهية الاجتماعية للعاملين يحسن من نظرة المجتمع للشركة. ب. الإفصاح عن البعد البيئي لمحاسبة التنمية المستدامة من خلال: - الاهتمام بتقليل الانبعاث الضارة بسبب الأنشطة مؤشر على اهتمام الثركة بالقضايا البيئية. - الاهتمام بتوفير أجهزة لتقليل التلوث البيئي يدل على إدراك الشركة للقضايا البيئية. - - القيام بتحمل أب تكاليف لإصلاح البيئة الخارجية يحسن من نظرة المجتمع للشركة. - الاهتمام بعرض التكاليف البيئية بالتقارير المالية يدعم نقة المستخدمين لهذه التقارير - الاهتمام بإصدار تقارير الأداء البيئي يوفر معلومات ملائمة لاتخاذ القرارات. ج. الإفصاح عن البعد الاقتصادي لمحاسبة التنمية المستدامة من خلال: - الاهتمام بالإفصاح عن معلومات القيمة الاقتصادية يؤدي إلى زيادة الأهمية النسبية للتقارير المالية. - الإفصاح عن الغرامات المفروضة على الثركة يدل على مصداقية التقارير المالية. - الاهتمام بتوفير السلع للمستهلكين دون احتكار يدل على قوة الثركة الإيرادية. - الإفصاح عن الحصة السوقية الحالية والمستقبلية يمكن من التتبؤ بالتدققات النقدية للشركة. - - احترام قواعد المنافسة السوقية بين الثركات يدعم تعزيز سمعة الشركة. رابعاً: إجراءات الاراسة الميدانية:

1/ مجتمـع وعينـة الاراسـة: يقصد بمجتمع الدراسـة المجموعة الكلية من العناصر التي يسعى الباحث أن يعمح عليها النتائج ذات العلاقة بالمشكلة المدروسة حيث يتمثل مجتمع الدراسة في دراسة ميدانية على وزارة المالية والتخطبط الاقتصادي أما عينة الدراسة فقد ثم اختيارها عشوائياً من مجتمع الدراسة حيث قام الباحث بتوزيــع عـدد (120) اسـتبانة على المسـتهدفين واسـتجاب (120) فـرداً أي نسـبة الاسـنبانة المسـتردة بلغت(100.0\%) وهذه النسبة تؤدي إلي قبول نتائج الدراسة وبالتالي تعميمها على مجتمع الدراسة. 
خامساً: اختبار البيانات الأساسية: الفرضية الأولى: "توجد علاقة ذات دلالة إحصائية بين الالتزام بالبعد الاجتماعي لمحاسبة التنمية المستدامة وتحسين المحتوي الإعلامي للتقارير المالية".

$$
\text { الجدول (1) }
$$

التوزيع التكراري لإجابات أفراد عينة الدراسة لعبارات الفرضية الأولى:

\begin{tabular}{|c|c|c|c|c|c|c|c|c|c|c|c|}
\hline & & & & لنسبة \% & & & & & & & \\
\hline بشدة & & فق & & & & وافق & & ك بثدة & لا أوا & & \\
\hline ن & ك5 & ن ن & 5 & ن ن & كs & ن & ك & ن ن & s & & \\
\hline$\% 60$ & 90 & $\% 25.3$ & 38 & $\% 3.3$ & 5 & $\% 3.3$ & 5 & $\% 8$ & 12 & 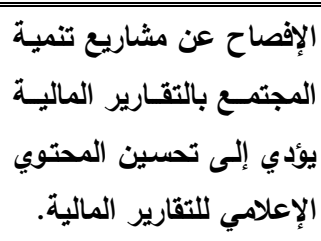 & 1 \\
\hline$\% 49.3$ & 74 & $\% 31.3$ & 47 & $\% 8$ & 12 & $\% 4$ & 6 & $\% 7.3$ & 11 & 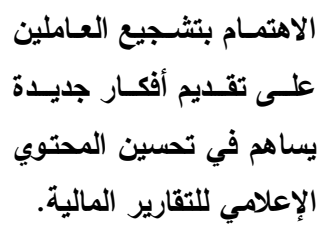 & 2 \\
\hline$\% 45.3$ & 68 & \%28.7 & 43 & $\% 10$ & 15 & $\% 13.3$ & 20 & $\% 2.7$ & 4 & 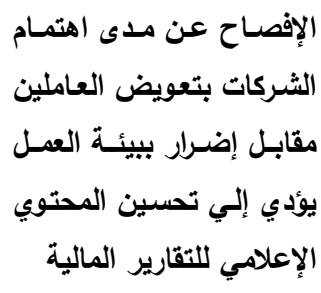 & 3 \\
\hline$\% 55.3$ & 83 & $\% 24.7$ & 37 & $\% 9.3$ & 14 & $\% 2.7$ & 4 & $\% 8$ & 12 & 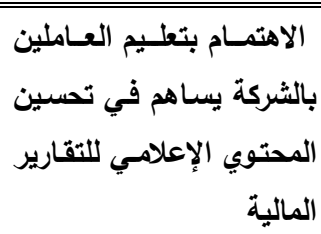 & 4 \\
\hline$\% 50.7$ & 76 & $\% 23.3$ & 35 & $\% 6.7$ & 10 & $\% 16.7$ & 25 & $\% 2.7$ & 4 & 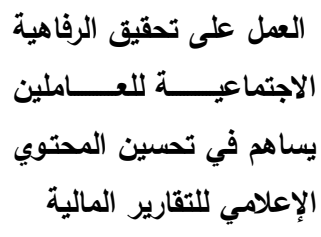 & 5 \\
\hline
\end{tabular}


دور المحاسبة عن التنمية المستدامة في تحسين المحتوى الإعلامي للتقارير المالية- د. آدم الطيب حهاد حامد

\begin{tabular}{|c|c|c|c|c|c|c|c|c|c|c|c|}
\hline$\% 607$ & 91 & $\% 19.3$ & 29 & $\% 8.7$ & 13 & $\% 2.7$ & 4 & $\% 8.7$ & 13 & 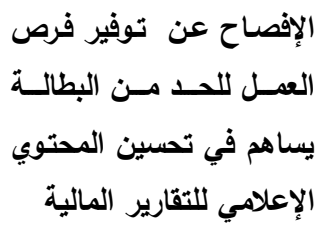 & 6 \\
\hline$\% 49.3$ & 74 & $\% 29.3$ & 44 & $\% 11.3$ & 17 & $\% 3.3$ & 5 & $\% 6.7$ & 10 & 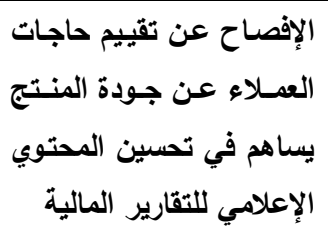 & 7 \\
\hline$\% 57.3$ & 86 & $\% 16$ & 24 & $\% 12.7$ & 19 & $\% 4$ & 6 & $\% 10$ & 15 & 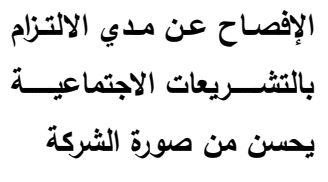 & 8 \\
\hline$\% 56$ & 84 & $\% 17.3$ & 26 & $\% 10$ & 15 & $\% 12$ & 18 & $\% 4.7$ & 7 & 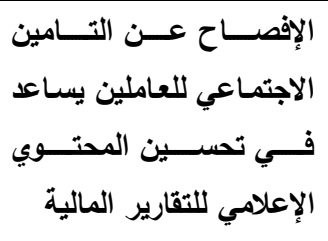 & 9 \\
\hline$\% 48$ & 72 & $\% 23.3$ & 35 & $\% 6$ & 9 & $\% 14$ & 21 & $\% 8.7$ & 13 & 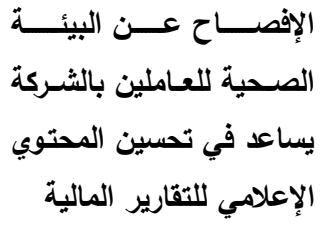 & 10 \\
\hline
\end{tabular}

المصدر : إعداد الباحث من الدراسة الميدانية، 2020م

من خلص الجدول (1) والذي يوضح النسب والتكرارات لعبارات الفرضية التي تنص على: "توجد علاقة ذات دلالة إحصائية بين الالتزام بالبعد الاجتماعي لمحاسبة التتمية المستدامة وتحسين المحتوي الإعلامي للتقارير

المالبة "

بلاحظ الباحث في العبارة الأولى القائلة "الإفصـاح عن مشـاريع تتميـة المجتمع بالتقارير المالية يؤدي إلى تحسين المحتوي الإعلامسي للتقارير المالية "نجد أن (128) مبحوث وبنسبة (85.3\%) من العينـة يوافقون على ما جاء بالعبارة، و (5) مبحوث وبنسبة (3.3\%) محايد، بينما يوجد (17) مبحوث من لا يوافق من العينة المبحوثة وبنسبة (11.3\%). 
العبارة الثانية: والتي تتص على"الاهتمام بتشجيع العاملين على تقديم أفكار جديدة يساهم في تحسين المحتوي الإعلامهي للتقارير الماليـة" نجد أن (121) مبحوث وبنسبة (80.6\%) من العينة يوافقون على مـا جاء بالعبارة، و (12) مبحوث وبنسبة (8\%) محايد، بينما يوجد (17) مبحوث من لا يوافق من العينة المبحوثة وبنسبة (11.3\%). العبارة الثالثة: والتي تنص على "الإفصاح عن مدى اهتمام الثركات بتعويض العاملين مقابل إضرار بييئة العمل يؤدي إلي تحسين المحتوي الإعلامي للتقارير المالية" نجد أن (111) مبحوث وبنسبة (74\%) من العينة يوافقون على ما جاء بالعبارة، و (15) مبحوث وبنسبة (10\%) محايد، بينما يوجد (24) مبحوث من لا يوافق من العينة المبحوثة وبنسبة (16\%). أما العبارة الرابعة التي تنص على " الاهتمام بتعليم العاملين بالثركة يساهم في تحسين المحتوي الإعلامي للتقارير المالية " نجد أن (120) مبحوث وبنسبة (80\%) من العينة يوافقون على ما جاء بالعبارة، و(14) مبحوث وبنسبة (9.3\%) محايـد، بينمـا يوجد (16) مبحوث مـن لا يوافق مـن العينـة المبحوثـة وبنسبة .$(\% 10.7)$

العبارة الخامسـة:" العمل على تحقيق الرفاهية الاجتماعيـة للعاملين يسـاهم في تحسين المحتوي الإعلامي للتقارير المالية " نجد أن (111) مبحوث وبنسبة (74\%) من العينة يوافقون على ما جاء بالعبارة، و (10) مبحوث وبنسبة (6.7\%) محايـد، بينمـا يوجد (29) مبحوث مـن لا يوافق مـن العينـة المبحوثـة وبنسبة .$(\% 19.4)$

العبارة السادسة: والتي تتص على" الإفصاح عن توفير فرص العمل للحد من البطالة يساهم في تحسين المحتوي الإعلامي للتقارير المالية " نجد أن (120) مبحوث وبنسبة (80\%) من العينة يوافقون على ما جاء بالعبارة، و (13) مبحوث وبنسبة (8.7\%) محايد، بينما يوجد (17) مبحوث لا يوافق على العينة المبحوثة وبنسبة (11.4\%).

العبارة السابعة: والتي تنص على" الإفصاح عن تقيم حاجات العملاء عن جودة المنتج يساهم في تحسين المحتوي الإعلامي للتقارير المالية " نجد أن (118) مبحوث وبنسبة (78.6\%) من العينة يوافقون على ما جاء بالعبارة، و (17) مبحوث وبنسبة (11.3\%) محايد، بينما يوجد (15) مبحوث من لا يوافق من العينة المبحوثة وبنسبة (10\%). 
العبارة الثامنة: والتي تتص على" الإفصاح عن مدي الالتزام بالتشريعات الاجتماعية يحسن من صورة الثركة " نجد أن (110) مبحوث وبنسبة (73.3\%) من العينـة يوافقون على مـا جاء بالعبارة، و (19) مبحوث

وبنسبة (127\%) محايد، بينما يوجد (21) مبحوث من لا يوافق من العينة المبحوثة وبنسبة (14\%). العبارة التاسعة: والتي تنص على"الإفصـاح عن التامين الاجتماعي للعاملين يساعد في تحسين المحتوي الإعلامسي للتقارير الماليـة "نجد أن (110) مبحوث وبنسبة (73.3\%) من العينـة يوافقون على مـا جاء بالعبارة، و (15) مبحوث وبنسبة (10\%) محايد، بينما يوجد (25) مبحوث من لا يوافق من العينة المبحوثة وبنسبة (16.7\%).

العبارة العاشرة: والتي تتص على"الإفصاح عن البيئة الصحية للعاملين بالثركة بساعد في تحسين المحتوي الإعلامسي للتقارير الماليـة "نجد أن (107) مبحوث وبنسبة (71.3\%) من العينة يوافقون على مـا جـاء بالعبارة، و (9) مبحوث وبنسبة (6\%) محايد، بينما يوجد (34) مبحوث من لا يوافق من العينة المبحوثنة وبنسبة (22.7\%).

ب/ جدول الإحصاء الوصفي لإجابات أفراد عينة الدراسة لعبارات الفرضية الأولى

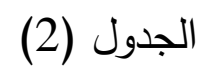

الإحصاء الوصفي لإجابات أفراد عينة الدراسة لعبارات الفرضية الأولى:

\begin{tabular}{|c|c|c|c|c|c|c|c|}
\hline التزتيب & الموافقة & الأهمبة & المنوا & المتوسد & 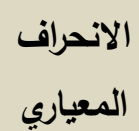 & 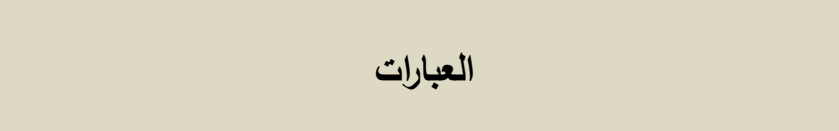 & ت \\
\hline 1 & جالية & $\% 85.2$ & 5 & 4.26 & 1.19 & الإلى تحسين المحتوي الإعلامي للتقارير المالية. & 1 \\
\hline 4 & 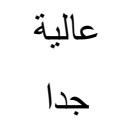 & $\% 82.2$ & 5 & 4.11 & 1.17 & تحسين المحتوي الإعلاميع اللتقارير المالية. & 2 \\
\hline 9 & جالية & $\% 80$ & 5 & 4.00 & 1.15 & 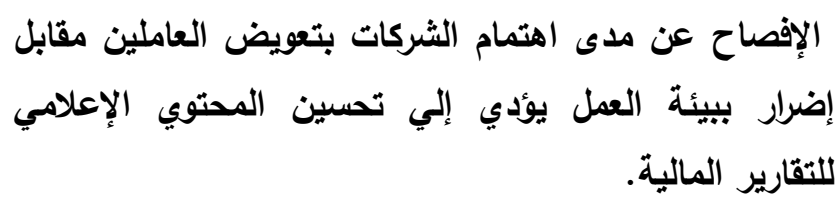 & 3 \\
\hline 3 & عالية & $\% 83.2$ & 5 & 4.16 & 1.20 & الاهتمام بتعليم العاملين بالثركة يساهم في تحسين المحتوي & 4 \\
\hline
\end{tabular}




\begin{tabular}{|c|c|c|c|c|c|c|c|}
\hline & جدا & & & & & الإعلامي للتقارير المالية. & \\
\hline 8 & جالية & $\% 80.4$ & 5 & 4.02 & 1.22 & تحسين المحتوي الإعلامي للتقارير المالية العقية للعاملين يساهم في & 5 \\
\hline 2 & جالية & $\% 84$ & 5 & 4.20 & 1.24 & 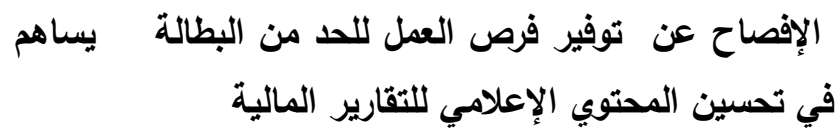 & 6 \\
\hline 5 & عالية & $\% 82.2$ & 5 & 4.11 & 1.15 & في تحسين المحتوي الإعلاهي للتقارير المالية عودة العتيم العنتج يساهم & 7 \\
\hline 7 & عالية & $\% 81.2$ & 5 & 4.06 & 1.32 & صورة الإفصاح عن مدي الالتزام بالتشريعات الاجتماعية يحسن من & 8 \\
\hline 6 & جالية & $\% 81.6$ & 5 & 4.08 & 1.25 & 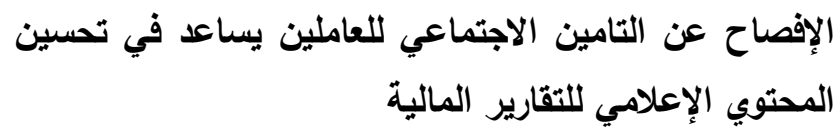 & 9 \\
\hline 10 & عالية & $\% 77.6$ & 4 & 3.88 & 1.37 & تحسين المحتوي الإعلامي للتقارير المالية للعاملين بالثركة يساعد في & 10 \\
\hline
\end{tabular}

المصدر : إعداد الباحث من الدراسة الميدانية، 2020م

من خلا الجدول (2) نلاحظ أن الإحصاءات الوصفية للعبارات الفرضية الأولى التي ينص على (توجد علاقـة ذات دلالـة إحصـائية بين الالتزام بالبعد الاجتمـاعي لمحاسبة التتميـة المستـامة وتحسين المحتوي الإعلامي للنقارير المالية) فان الأوساط الحسابية له تقع في المدى ما بين (3.88- 4.26) والمنوال (4-5) والانحراف المعياري يقع في المدى مـابين (1.15 - 1.37) لجميع العبارات وحسب المقيـاس الخماسي ليكرت فان إجابات المبحوثين هي المحايدة والموافقة والموافقة بثدة. 
دور المحاسبة عن التنمية المستدامة في تحسين المحتوى الإعلامي للتقارير المالية- د. آدم الطيب حهاد حامد

الجدول (3):اختبار مربع كاى لعبارات الفرضية الأولى:

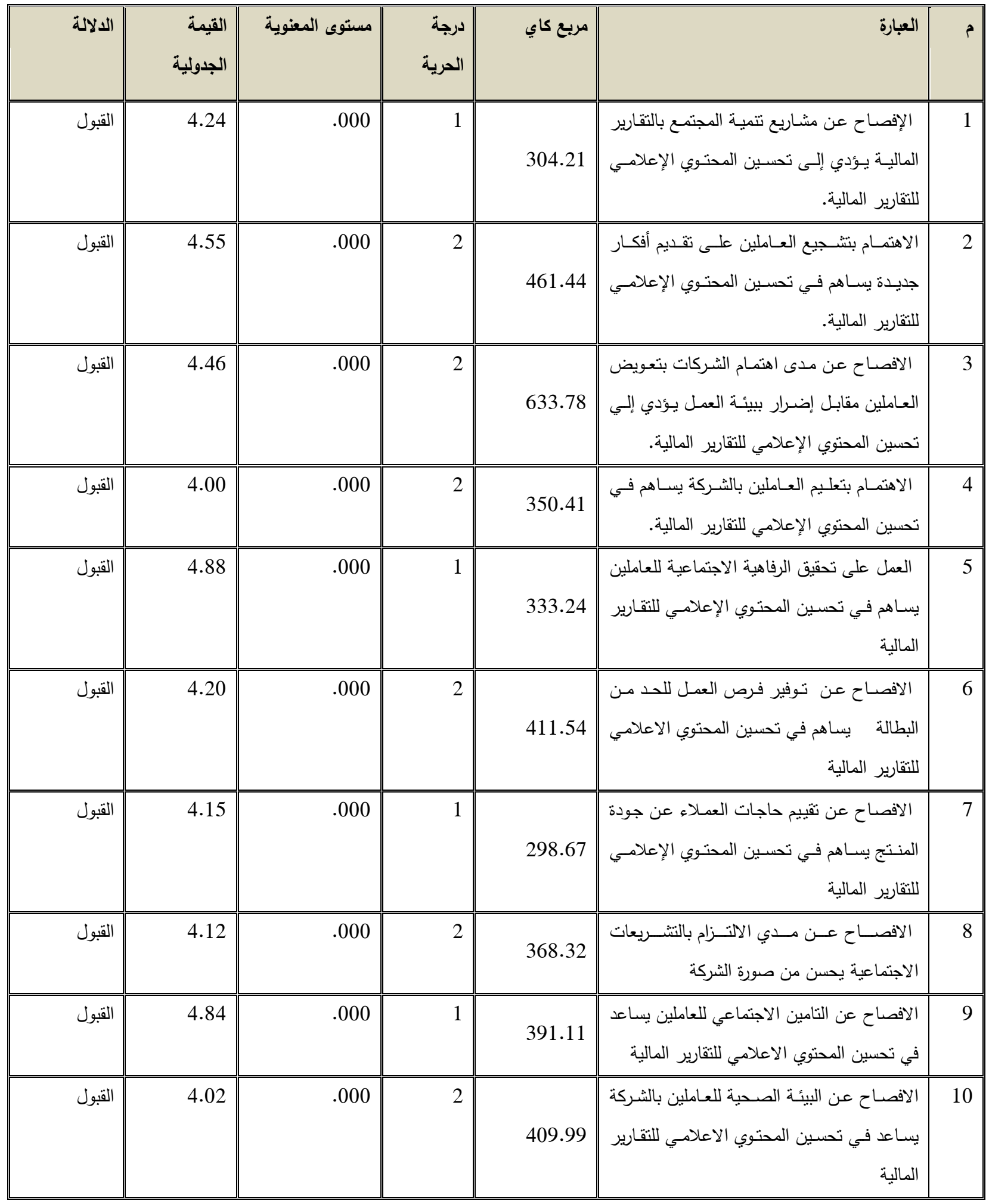

المصدر : إعداد الباحث، من الدراسة الميدانية،2020م 
يتضـح من خـلال (3) لاختبار صحة الفرضية التي تنص على:" توجد علاقة ذات دلالة احصـائية بين الالتزام بالبعد الاجتمـاعي لمحاسبة التتميـة المستـامة وتحسين المحتوي الاعلامسي للتقارير الماليـة " تم استخدام اختبار مربع كاي لعبارات المحور وجاءت قيم مربع كاي المحسوبة (304.21 - 461.44 $(409.99$ - 391.11 - 368.32 - 298.67 - 411.54 - 333.24 - 350.41 - 633.78 والقيمة الجدولية تقع في الددى ما بين (4.00 - 4.88) وبدرجات حرية (2-1) وبمستوى دلالة Sig لجميع العبارات (0.00) وعند مقارنـة مسنوى الدلالـة sig بمستوى المعنويـة المسموح بـ (0.05) نجد أن مستوى الدالة sig تقل عن مستوى المعنوية مما يعني وجود فروق ذات دلالة إحصائية لعبارات الفرضية. الفرضية الثانية: " توجد علاقة ذات دلالة احصائية بين الالتزام بالبعد البيئي لمحاسبة التنمية المستدامة وتحسين المحتوي الاعلامي للتقاريز المالية" الجدول (4):التوزيع التكراري لإجابات أفراد عينة الدراسة لعبارات الفرضية الثانية:

\begin{tabular}{|c|c|c|c|c|c|c|c|c|c|c|c|}
\hline & & & & والنسب & & & & & & & \\
\hline ق بثدة & & إقق & & حايد & & أوافق & & وافق & & & قم \\
\hline ن & s) & ن & ك & ن & ك5 & ن ن & ك5 & ن & ك & & \\
\hline$\% 57.3$ & 86 & $\% 22.7$ & 34 & $\% 2$ & 3 & $\% 14.7$ & 22 & $\% 3.3$ & 5 & 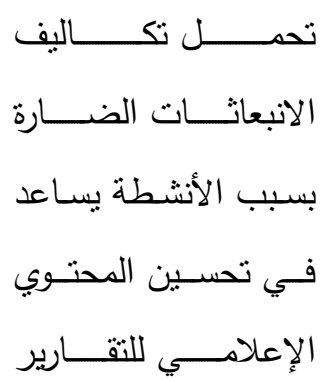 & 1 \\
\hline$\% 52$ & 78 & $\% 26.7$ & 40 & $\% 8$ & 12 & $\% 4.7$ & 7 & $\% 8.7$ & 13 & 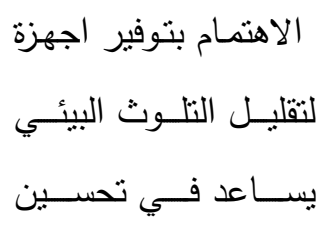 & 2 \\
\hline
\end{tabular}


دور المحاسبة عن التنمية المستدامة في تحسين المحتوى الإعلاي للتقارير المالية- د. آدم الطيب حهاد حامد

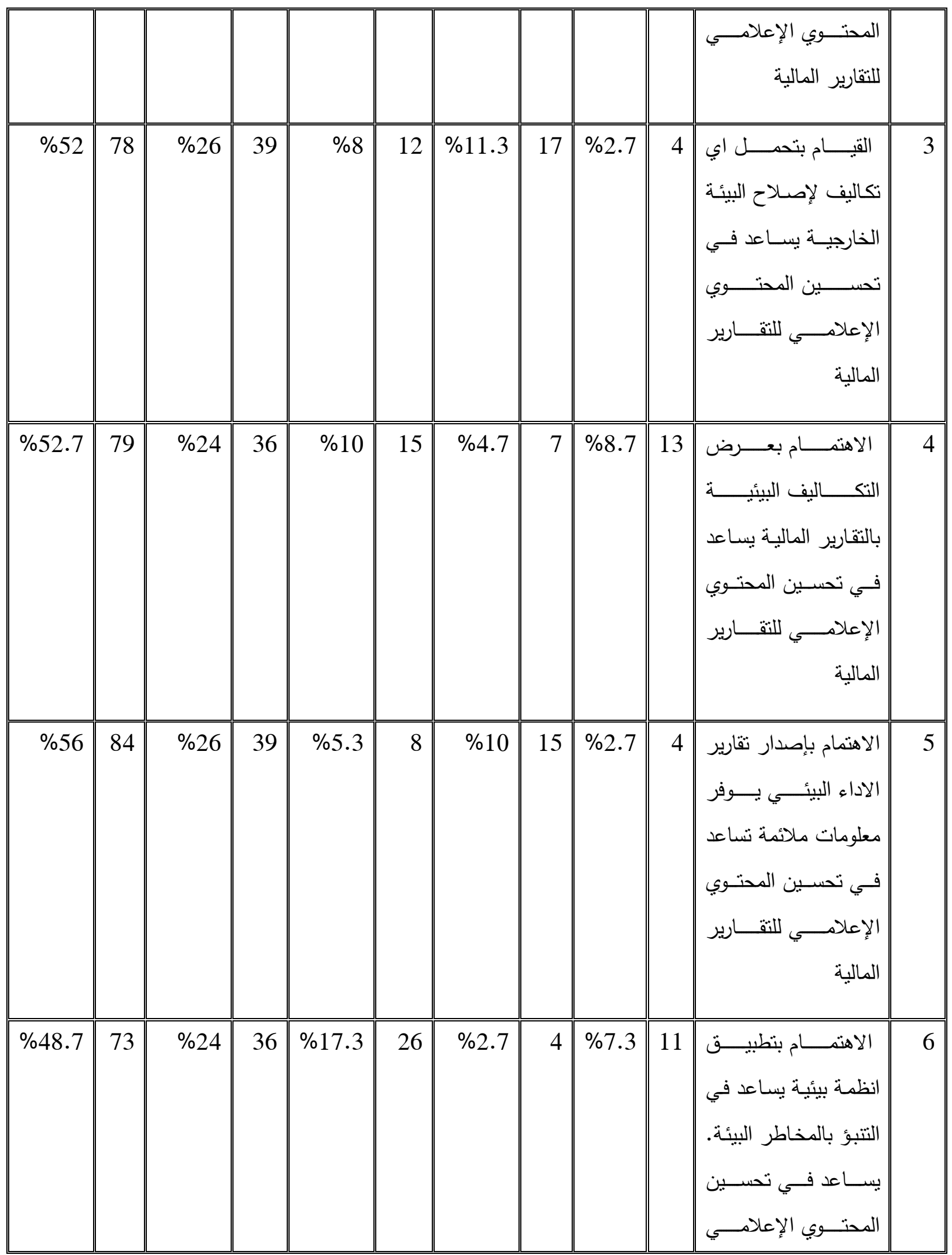




\begin{tabular}{|c|c|c|c|c|c|c|c|c|c|c|c|}
\hline & & & & & & & & & & للتقارير المالية & \\
\hline$\% 52$ & 78 & $\% 28$ & 42 & $\% 8$ & 12 & $\% 9.3$ & 14 & $\% 2.7$ & 4 & 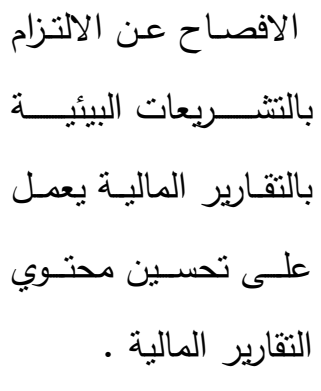 & 7 \\
\hline$\% 52.7$ & 79 & $\% 25.3$ & 38 & $\% 9.3$ & 14 & $\% 5.3$ & 8 & $\% 7.3$ & 11 & 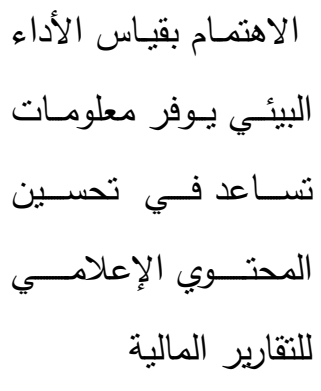 & 8 \\
\hline$\% 57.3$ & 86 & $\% 18.7$ & 28 & $\% 4$ & 6 & $\% 17.3$ & 26 & $\% 2.7$ & 4 & 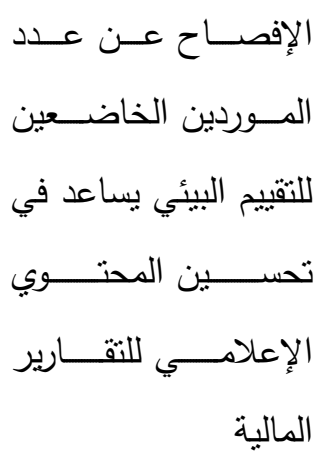 & 9 \\
\hline$\% 50$ & 75 & $\% 32$ & 48 & $\% 6$ & 9 & $\% 4.7$ & 7 & $\% 7.3$ & 11 & 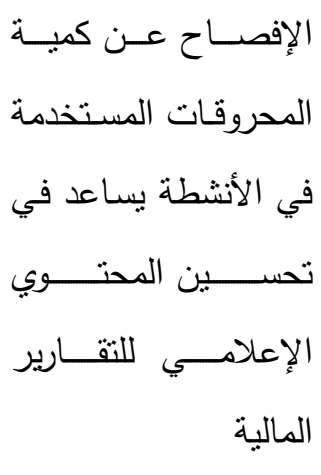 & 10 \\
\hline
\end{tabular}


من خلا الجدول (4) والذي يوضح النسب والتكرارات لعبارات الفرضية التي تنص على:" توجد علاقة ذات دلالة إحصائية بين الالتزام بالبعد البيئي لمحاسبة التتميـة المستدامة وتحسين المحتوي الإعلامي للتقارير المالية"

يلاحظ الباحث في العبارة الأولى القائلة " تحمل تكاليف الانبعاثات الضارة بسبب الأنشطة يساعد في تحسين المحتوي الإعلامي للتقارير المالية"تجد أن (120) مبحوث وبنسبة (80\%) من العينة يوافقون على ما جاء بالعبارة، و (3) مبحوث وبنسبة (2\%) محايد، بينما يوجد (27) مبحوث من لا يوافق من العينة المبحوثة وبنسبة (18\%).

العبارة الثانيـة: والتي تنص على" الاهتمام بتوفير أجهزة لتقليل التلوث البيئي يساعد في تحسين المحتوي الإعلادهي للتقارير الماليـة " نجد أن (118) مبحوث وبنسبة (78.7\%) من العينـة يوافقون على مـا جاء بالعبارة، و (12) مبحوث وبنسبة (8\%) محايد، بينما يوجد (20) مبحوث من لا يوافق من العينة المبحوثة وبنسبة (13.4\%).

العبارة الثالثة: والتي تنص على "القيام بتحمل أي تكـاليف لإصـلاح البيئة الخارجيـة يسـاعد في تحسين المحتوي الإعلامي للتقارير المالية" نجد أن (117) مبحوث وبنسبة (78\%) من العينة يوافقون على ما جاء بالعبارة، و (12) مبحوث وبنسبة (8\%) محايد، بينما يوجد (21) مبحوث من لا يوافق من العينة المبحوثة

وبنسبة (14\%).

أمـا العبارة الرابعـة التي تنص على "الاهتمام بعرض التكاليف البيئية بالتقارير المالية يساعد في تحسين المحتوي الإعلامي للتقارير المالية "نجد أن (115) مبحوث وبنسبة (76.7\%) من العينة يوافقون على ما جاء بالعبارة، و (15) مبحوث وبنسبة (10\%) محايد، بينما يوجد (20) مبحوث من لا يوافق من العينة المبحوثة وبنسبة (13.4\%).

العبارة الخامسة:" الاهتمام بإصدار تقارير الأداء البيئي يوفر معلومات ملائمة نساعد في تحسين المحتوي الإعلامي للتقارير المالية "نجد أن (123) مبحوث وبنسبة (82\%) من العينة يوافقون على ما جاء بالعبارة، و (8) مبحوث وبنسبة (5.3\%) محايد، بينما يوجد (19) مبحوث من لا يوافق من العينة المبحوثة وبنسبة 
العبارة السادسة: والتي تنص على" الاهتمام بتطبيق أنظمة بيئية يساعد في التنبؤ بالمخاطر البيئة. يساعد في تحسين المحتوي الإعلامي للتقارير المالية "نجد أن (109) مبحوث وبنسبة (72.7\%) من العينة يوافقون على ما جاء بالعبارة، و (26) مبحوث وبنسبة (17.3\%) محايد، بينما يوجد (15) مبحوث من لا يوافق من العينة المبحوثة وبنسبة (10\%). العبارة السـابعة: والتي تنص على" الإفصـاح عن الالتزام بالتشـريعات البيئية بالتقارير الماليـة يعدل على تحسين محتوي التقارير المالية " نجد أن (120) مبحوث وبنسبة (80\%) من العينة يوافقون على ما جاء بالعبارة، و (12) مبحوث وبنسبة (8\%) محايد، بينما يوجد (18) مبحوث من لا يوافق من العينة المبحوثة وبنسبة (12\%).

العبارة الثامنة: والتي تنص على" الاهتمام بقياس الأداء البيئي يوفر معلومات تساعد في تحسين المحتوي الإعلامي للتقارير المالية " نجد أن (117) مبحوث وبنسبة (78\%) من العينة يوافقون على ما جاء بالعبارة، و (14) مبحوث وبنسبة (9.3\%) محايد، بينمـا يوجد (19) مبحـوث مـن لا يوافق على العينـة المبحوثـة وبنسبة (12.6\%).

العبارة التاسعة: والتي تنص على" الإفصاح عن عدد الموردين الخاضعين للتقييم البيئي بساعد في تحسين المحتوي الإعلامي للتقارير المالية "ند أن (114) مبحوث وبنسبة (76\%) من العينة يوافقون على ما جاء بالعبارة، و (6) مبحوث وبنسبة (4\%) محايد، بينما يوجد (30) مبحوث من لا يوافق من العينة المبحوثة وبنسبة (20\%). العبارة العاثرة: والتي تتص على" الإفصاح عن كمية المحروقات المستخدمة في الأنشطة يساعد في تحسين المحتوي الإعلامي للتقارير المالية "نجد أن (123) مبحوث وبنسبة (82\%) من العينة يوافقون على ما جاء بالعبارة، و (9) مبحوث وبنسبة (\%) محايد، بينما يوجد (18) مبحوث من لا يوافق من العينة المبحوثة وبنسبة (12\%). 


\section{ب/ جدول الإحصاء الوصفي لإجابات أفراد عينة الاراسة لعبارات الفرضية الثانية:}

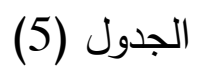

الإحصاء الوصفي لإجابات أفراد عينة الدراسة لعبارات الفرضية الثانية:

\begin{tabular}{|c|c|c|c|c|c|c|c|}
\hline 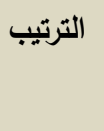 & درجة الموافقة & الأهمية النسبية & 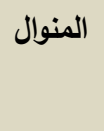 & 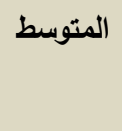 & المعياري & العبارات & ت \\
\hline 3 & عالية جدا & $\% 83.2$ & 5 & 4.16 & 1.21 & 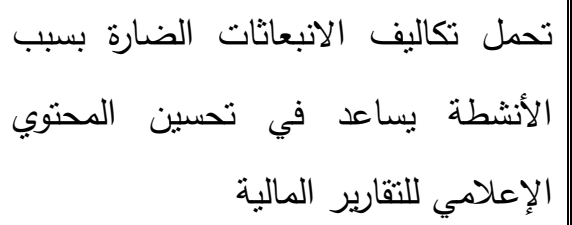 & 1 \\
\hline 8 & عالية جدا & $\% 81.6$ & 5 & 4.08 & 1.25 & 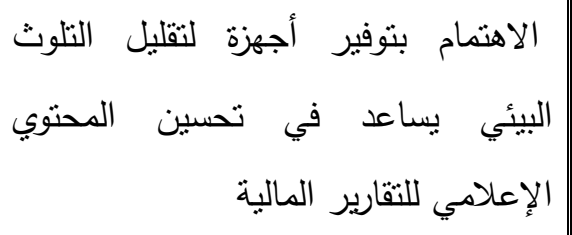 & 2 \\
\hline 6 & عالية جدا & $\% 82.6$ & 5 & 4.13 & 1.13 & 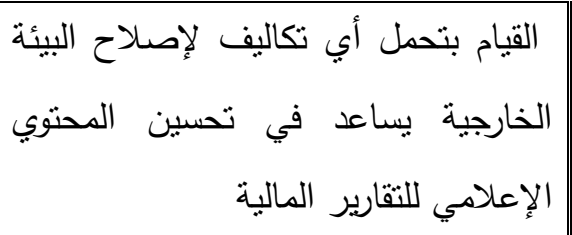 & 3 \\
\hline 9 & عالية جدا & $\% 81.4$ & 5 & 4.07 & 1.26 & 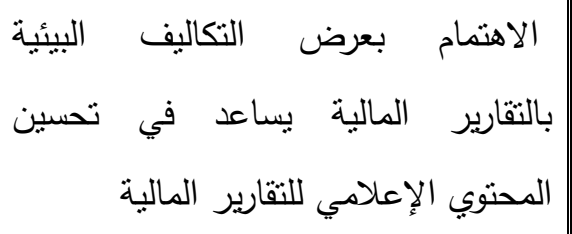 & 4 \\
\hline 1 & عالية جدا & $\% 84.4$ & 5 & 4.22 & 1.10 & 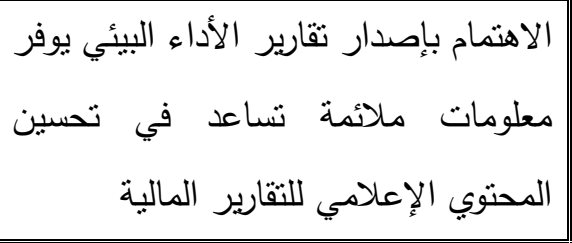 & 5 \\
\hline 10 & عالية جدا & $\% 80.2$ & 5 & 4.04 & 1.19 & 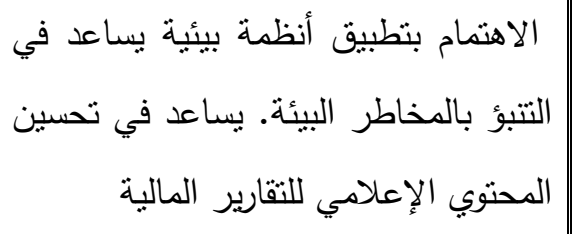 & 6 \\
\hline 2 & عالية جدا & $\% 83.4$ & 5 & 4.17 & 1.09 & 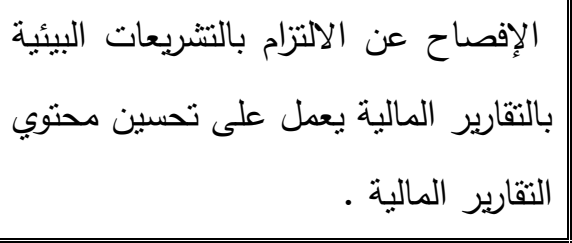 & 7 \\
\hline 7 & عالية جدا & $\% 82.2$ & 5 & 4.11 & 1.22 & الاهتمام بقياس الأداء البيئي يوفر & 8 \\
\hline
\end{tabular}




\begin{tabular}{|c|c|c|c|c|c|c|c|}
\hline & & & & & & الإعلامي للتقارير المالية تساعد في تحسين المحتوي & \\
\hline 5 & عالية جدا & $\% 82.6$ & 5 & 4.13 & 1.24 & الإلإفصليبح البيئي بساعد في عدد الموردين الخاضعين & 9 \\
\hline 4 & عالية جدا & $\% 82.8$ & 5 & 4.14 & 1.18 & الإفي الإعلاح عن كمية المحروقات المستخدمة & 10 \\
\hline
\end{tabular}

المصدر : إعداد الباحث من الدراسة الميدانية، 2020م

مـن خـلد الجدول (5) يلاحظ الباحثث أن الإحصـاءات الوصـفية للعبـارات الفرضـية الثانيـة التي ينص على"توجد علاقة ذات دلالة إحصائية بين الالتزام بالبعد البيئي لمحاسبة التتمية المستدامة وتحسين المحتوي الإعلامي للتقارير المالية" فان الاوساط الحسابي له تقع في المدى ما بين (4.04- 4.22) والمنوال (5) والانحراف المعياري يقع في المدى مـابين (1.09 - 1.26) لجميع العبارات وحسب المقياس الخماسي ليكرت فان إجابات المبحوثين هي موافق وموافق بثدة. الجدول (6) اختبار مربع كاى لعبارات الفرضية الثانية:

\begin{tabular}{|c|c|c|c|c|c|c|}
\hline الدلالة & الجديمة & مستوى & 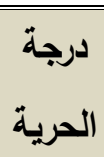 & مريع كاي & العبارة & م \\
\hline القبول & 4.50 & .000 & 2 & 330.33 & تحمل تكاليف الانبعاثات الضارة بسبب الأنشطة بساعد في تحسين & 1 \\
\hline القبول & 4.35 & .000 & 1 & 349.11 & الإِعلامي للتقارير المالية أجهزة لتقليل التلوث البيئي بساعد في تحسين المحتوي & 2 \\
\hline القبول & 4.42 & .000 & 2 & 461.38 & 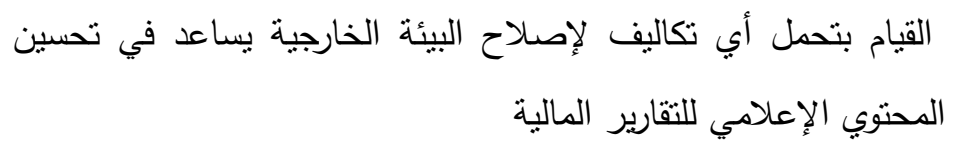 & 3 \\
\hline القبول & 4.24 & .000 & 1 & 291.14 & الاهتمام بعرض التكاليف البيئية بالتقارير المالية بساعد في تحسين & 4 \\
\hline
\end{tabular}


دور المحاسبة عن التنمية المستدامة في تحسين المحتوى الإعلاي للتقارير المالية- د. آدم الطيب حهاد حامد

\begin{tabular}{|c|c|c|c|c|c|c|}
\hline القبول & 4.93 & .000 & 1 & 370.45 & تالاهمام بإصدار تقارير الأداء البيئي يوفر معلومات ملائمة نساعد في & 5 \\
\hline القبول & 4.11 & .000 & 1 & 422.51 & 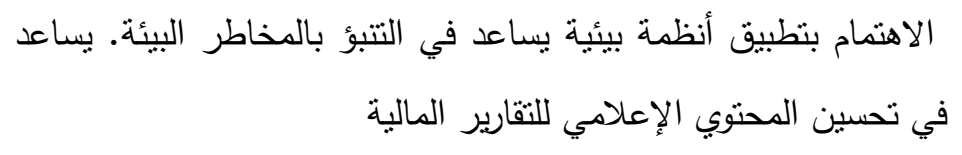 & 6 \\
\hline القبول & 4.25 & .000 & 2 & 319.44 & تحسين محتوي الثقارير المالية الإلتزام بالتشريعات البيئية بالتقارير المالية بعمل على & 7 \\
\hline القبول & 4.85 & .000 & 1 & 369.66 & الاهتمام بقياس الأداء البيئي يوفر معلومات تساعد في تحسين & 8 \\
\hline القبول & 4.65 & .000 & 2 & 346.46 & الإفصاح عن عدد الموردين الخاضعين للتقييم البيئي يساعد في تحسين & 9 \\
\hline القبول & 4.65 & .000 & 1 & 387.77 & تحسين الإفصناح عن كمية المحروقات المستخدمة في الأنشطة يساعد في & 10 \\
\hline
\end{tabular}

المصدر : إعداد الباحث، من الدراسة الميدانية، 2020م

يتضـح من خلال الجدول (6) لاختبـار صحة الفرضية التي تنص على: "توجد علاقة ذات دلالـة إحصائية بين الالتزام بالبعد البيئي لمحاسبة التتمية المستدامة وتحسين المحتوي الإعلامي للتقارير المالية"تم استخدام اختبار مربع كاي لعبارات الفرضية وجاءت قيم مربع كاي المحسوبة (330.33 - 349.11 $(387.77-346.46-369.66-319.44-422.51-370.45-291.14-461.38$ وبدرجة حربـة (1-2) والقيمة الجدولية تقع في المدى مابين (4.24 - 4.93) وبمستوى دلالة Sig لجميع العبارات (000.) وعند مقارنـة مستوى الدلالـة sig بمستوى المعنويـة المسموح بـه (0.05) نجد أن مستوى الدلالة sig تقل عن مستوى المعنوية مما يعني وجود فروق ذات دلالة إحصائية لعبارات. 
الفرضـية الثالثة: "توجد علاقـة ذات دلالـة إحصـائية بـين الالتزام بالبعد الاقتصـادي لمحاسبة التنميـة

المستدامة وتحسين المحتوي الإعلامي للتقاريز المالية "

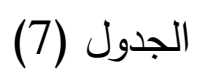

التوزيع التكراري لإجابات أفراد عينة الدراسة لعبارات الفرضية الثالثة:

\begin{tabular}{|c|c|c|c|c|c|c|c|c|c|c|c|}
\hline \multicolumn{10}{|c|}{ التكرار والنسبة \% } & \multirow[t]{3}{*}{ العبارة } & \multirow[t]{3}{*}{ الر } \\
\hline \multicolumn{2}{|c|}{ أوافق بثدة } & \multicolumn{2}{|c|}{ أوافق } & \multicolumn{2}{|c|}{ محايد } & \multicolumn{2}{|c|}{ لا أوافق } & \multicolumn{2}{|c|}{ لا أوافق بثدة } & & \\
\hline ن ن & ك & ن ن & ك5 & ن & ك5 & ن & ك & ن ن & ك & & \\
\hline$\% 52.7$ & 79 & $\% 23.3$ & 35 & $\% 10$ & 15 & $\% 8.7$ & 13 & $\% 5.3$ & 8 & 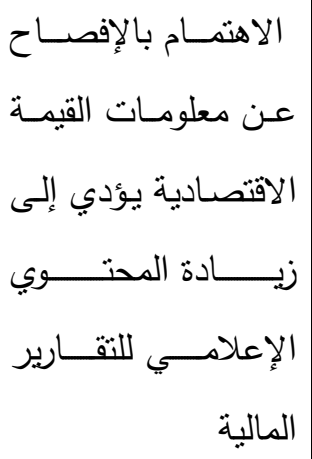 & 1 \\
\hline$\% 54$ & 81 & $\% 23.3$ & 35 & $\% 14.7$ & 22 & $\% 4.7$ & 7 & $\% 3.3$ & 5 & 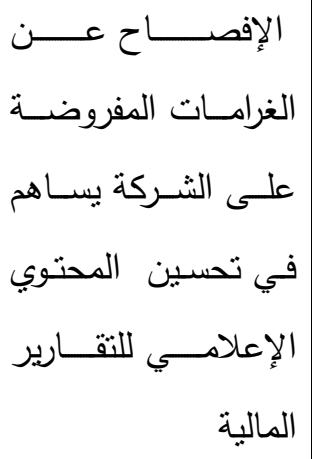 & 2 \\
\hline$\% 57.3$ & 86 & $\% 26$ & 39 & $\% 6$ & 9 & $\% 4$ & 6 & $\% 6.7$ & 10 & 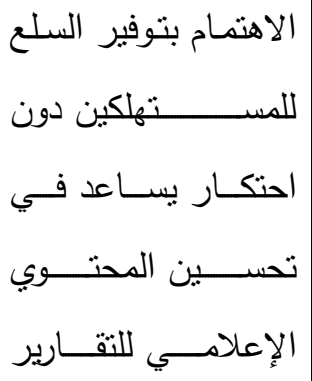 & 3 \\
\hline
\end{tabular}


دور المحاسبة عن التنمية المستدامة في تحسين المتوى الإعلامي للتقارير المالية- ـ د. آدم الطيب حهاد حامد

\begin{tabular}{|c|c|c|c|c|c|c|c|c|c|c|c|}
\hline & & & & & & & & & & المالية & \\
\hline$\% 52.7$ & 79 & $\% 25.3$ & 38 & $\% 9.3$ & 14 & $\% 9.3$ & 14 & $\% 3.3$ & 5 & 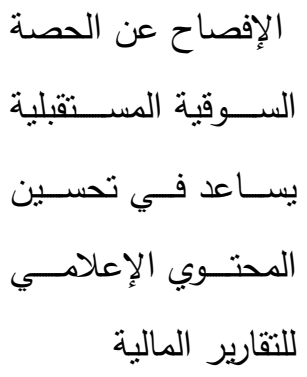 & 4 \\
\hline$\% 50$ & 75 & $\% 30.7$ & 46 & $\% 7.3$ & 11 & $\% 9.3$ & 14 & $\% 2.7$ & 4 & 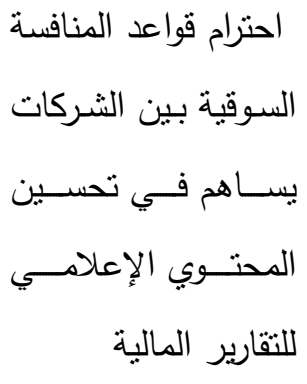 & 5 \\
\hline$\% 52$ & 78 & $\% 22.7$ & 34 & $\% 14.7$ & 22 & $\% 7.3$ & 11 & $\% 3.3$ & 5 & العـادة الإفــاح عن تلـوير النفايـات & 6 \\
\hline$\% 53.3$ & 80 & $\% 23.3$ & 35 & $\% 5.3$ & 8 & $\% 11.3$ & 17 & $\% 6.7$ & 10 & 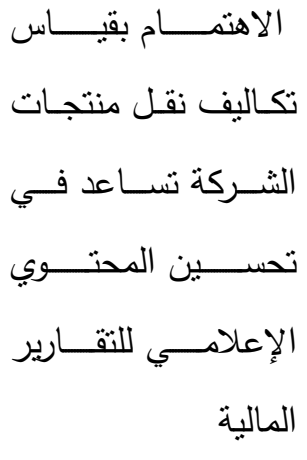 & 7 \\
\hline$\% 49.3$ & 74 & $\% 29.3$ & 44 & $\% 4.7$ & 7 & $\% 13.3$ & 20 & $\% 3.3$ & 5 & 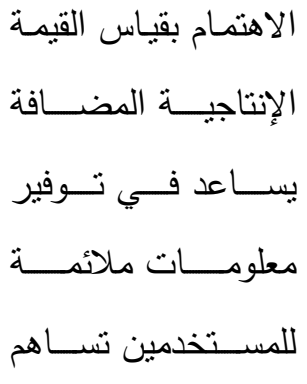 & 8 \\
\hline
\end{tabular}




\begin{tabular}{|c|c|c|c|c|c|c|c|c|c|c|c|}
\hline & & & & & & & & & & الإعي تحسين المحتــي & \\
\hline$\% 59.3$ & 89 & $\% 20.7$ & 31 & $\% 8$ & 12 & $\% 5.3$ & 8 & $\% 6.7$ & 10 & 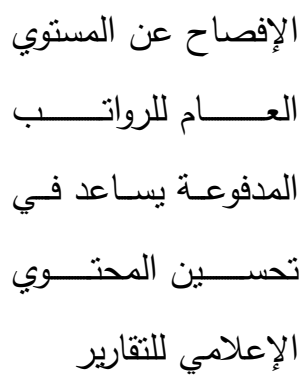 & 9 \\
\hline$\% 53.3$ & 80 & $\% 28.7$ & 43 & $\% 6$ & 9 & $\% 8.7$ & 13 & $\% 3.3$ & 5 & 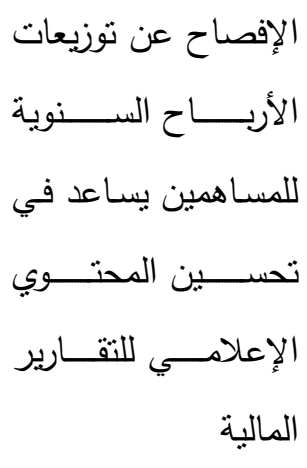 & 10 \\
\hline
\end{tabular}

المصدر : إعداد الباحثون من الدراسة الميدانية، 2020م

من خلا الجدول (7) والذي يوضح النسب والتكرارات لعبارات الفرضية التي تنص على:" توجد علاقة ذات دلالة إحصائية بين الالتزام بالبعد الاقتصادي لمحاسبة التتمية المستدامة وتحسين المحتوي الإعلامي للتقارير المالية " يلاحظ الباحث في العبارة الأولى القائلة "الاهتمام بالإفصاح عن معلومات القيمة الاقتصادية يؤدي إلى زيادة المحتوي الإعلامي للتقارير المالية" نجد أن (114) مبحوث وبنسبة (76\%) من العينة يوافقون على ما جاء بالعبارة، و (15) مبحوث وبنسبة (10\%) محايد، بينما يوجد (21) مبحوث من لا يوافق من العينة المبحوثة وبنسبة (14\%). العبارة الثانية: والتي تتص على" الإفصاح عن الغرامات المفروضة على الثركة بساهم في تحسين المحتوى الإعلامسي للتقارير المالية " نجد أن (116) مبحوث وبنسبة (77.3\%) من العينـة يوافقون على مـا جاء 
بالعبارة، و (22) مبحـوث وبنسبة (14.7\%) محايد، بينمـا يوجد (12) مبحـوث مـن لا يوافق من العينـة المبحوثة وبنسبة (8\%).

العبارة الثالثة: والتي تتص على " الاهتمام بتوفير السلع للمستهكين دون احتكار يساعد في تحسين المحتوي الإعلامسي للتقارير الماليـة" نجد أن (125) مبحوث وبنسبة (83.3\%) من العينة يوافقون على مـا جـاء بالعبارة، و (9) مبحوث وبنسبة (6\%) محايد، بينما يوجد (16) مبحوث من لا يوافق من العينـة المبحوثة وبنسبة (10.7\%).

أمسا العبارة الرابعة التي تنص على " الإفصـاح عن الحصـة السوقية المستقبلية يساعد في تحسين المحتوي الإعلامي للتقارير المالية"نجد أن (117) مبحوث وبنسبة (78\%) من العينة يوافقون على ما جاء بالعبـارة، و (14) مبحـوث وبنسبة (9.3\%) محايـد، بينمـا يوجد (19) مبحـوث مـن لا يوافق مـن العينـة المبحوثة وبنسبة (11.6\%). العبارة الخامسة:" احترام قواعد المنافسة السوقية بين الثركات بساهم في تحسين لمحتوي الإعلامي للتقارير المالية "نجد أن (121) مبحوث وبنسبة (80.7\%) من العينة يوافقون على ما جاء بالعبارة، و (11) مبحوث وبنسبة (7.3\%) محايد، بينما يوجد (18) مبحوث من لا يوافق من العينة المبحوثة وبنسبة (12\%). العبارة السادسة: والتي تنص على" الإفصاح عن تكاليف إعادة تدوير النفايات يساهم في تحسين المحتوي الإعلامسي للتقارير المالية " نجد أن (112) مبحوث وبنسبة (74.7\%) من العينـة بوافقون على مـا جاء بالعبارة، و (22) مبحوث وبنسبة (14.7\%) محايد، بينمـا يوجد (16) مبحوث مـن لا يوافق من العينـة المبحوثة وبنسبة (10.6\%).

العبارة السابعة: والتي تنص على"الاهتمام بقياس تكاليف نقل منتجات الثركة تساعد في تحسين المحتوي الإعلامسي للتقارير الماليـة "نجد أن (115) مبحوث وبنسبة (76.6\%) من العينة يوافقون على مـا جـاء بالعبارة، و (8) مبحوث وبنسبة (5.3\%) محايد، بينما يوجد (27) مبحوث من لا يوافق من العينة المبحوثة وبنسبة (18\%). العبارة الثامنة: والتي تتص على" الاهتمام بقياس القيمة الإنتاجية المضافة يساعد في توفير معلومات ملائمة للمسـتخدمين تسـاهم في تحسـين المحتوي الإعلامسي للتقـارير الماليـة " نجد أن (118) مبحسوث وبنسـبة 
(78.6\%) من العينة يوافقون على ما جاء بالعبارة، و (7) مبحوث وبنسبة (4.7\%) محايد، بينما يوجد (25) مبحوث من لا يوافق من العينة المبحوثة وبنسبة (16.6\%).

العبارة التاسعة: والتي تتص على"الإفصاح عن المستوي العام للرواتب الددفوعة يساعد في تحسين المحتوي الإعلامهي للتقارير " نجد أن (120) مبحوث وبنسبة (80\%) من العينـة يوافقون على مـا جاء بالعبارة، و (12) مبحوث وبنسبة (8\%) محايد، بينما يوجد (18) مبحوث من لا يوافق من العينـة المبحوثة وبنسبة .$(\% 12)$

العبارة العاشـرة: والتي تنص على" الإفصـاح عن توزيعات الأرباح السنوية للمساهمين يساعد في تحسين المحتوي الإعلامي للتقارير المالية "نجد أن (123) مبحوث وبنسبة (82\%) من العينة يوافقون على ما جاء بالعبارة، و (9) مبحوث وبنسبة (6\%) محايد، بينما يوجد (18) مبحوث من لا يوافق من العينة المبحوثة وبنسبة (12\%). ب/ جدول الإحصاء الوصفي لإجابات أفراد عينة الدراسة لعبارات الفرضية الثالثة:

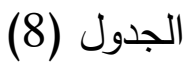

الإحصاء الوصفي لإجابات أفراد عينة الدراسة لعبارات الفرضية الثالثة:

\begin{tabular}{|c|c|c|c|c|c|c|c|}
\hline الترتيب & الموافقة & الأهمية & المنوال & المتوسط & المعياري & العبارات & ت \\
\hline 8 & عالية جدا & \%81.8 & 5 & 4.09 & 1.20 & 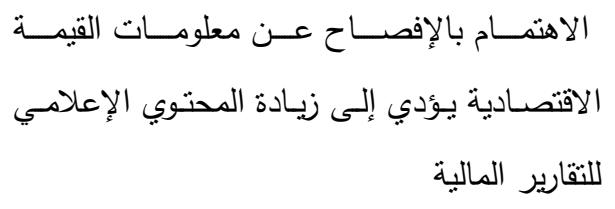 & 1 \\
\hline 4 & عالية جدا & $\% 84$ & 5 & 4.20 & 1.07 & المساهم في تحسين الإفصاح عن الغرامات المفروضـة على الثـركة الإعلامسي للتقارير & 2 \\
\hline 1 & عالية جدا & $\% 84.6$ & 5 & 4.23 & 1.16 & 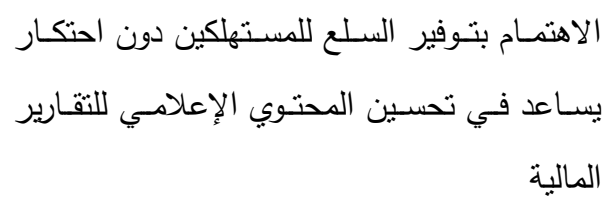 & 3 \\
\hline 6 & عالية جدا & \%82.8 & 5 & 4.14 & 1.13 & 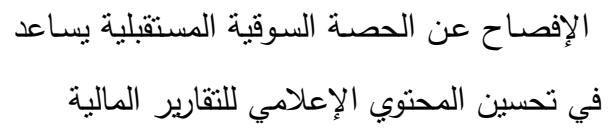 & 4 \\
\hline
\end{tabular}


دور المحاسبة عن التنمية المستدامة في تحسين المتوى الإعلامي للتقارير المالية- ـ د. آدم الطيب حماد حامد

\begin{tabular}{|c|c|c|c|c|c|c|c|}
\hline 5 & عالية جدا & $\% 83.2$ & 5 & 4.16 & 1.08 & 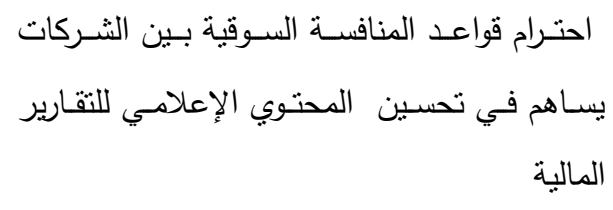 & 5 \\
\hline 7 & عالية جدا & $\% 82.4$ & 5 & 4.12 & 1.11 & 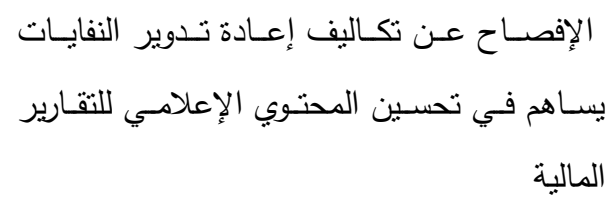 & 6 \\
\hline 10 & عالية جدا & $\% 81$ & 5 & 4.05 & 1.28 & الالهــــام بقيـاس تكاليف نقل منتجـات الثـركة & 7 \\
\hline 9 & عالية جدا & $\% 81.6$ & 5 & 4.08 & 1.17 & تحسين الاهتمـام بقيـاس القيمة الإنتاجيـة المضـافة يسـاعد & 8 \\
\hline 3 & عالية جدا & \%84 & 5 & 4.20 & 1.20 & الإفصـاح عـن المسـتوي العـام للرواتب المدفوعـة & 9 \\
\hline 2 & عالية جدا & $\% 84.2$ & 5 & 4.21 & 1.09 & 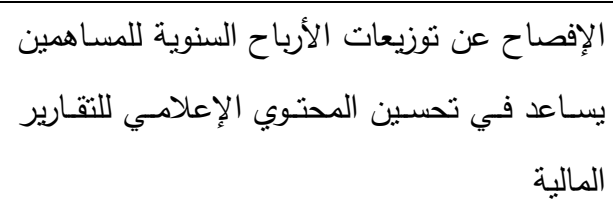 & 10 \\
\hline
\end{tabular}

المصدر : إعداد الباحث من الدراسة الميدانية، 2020م

من خـلال الجدول (8) يلاحظ الباحث أن الإحصـاءات الوصفية للعبارات الفرضية التي ينص على"توجد علاقـة ذات دلالـة إحصـائية بين الالتزام بالبعد الاقتصـادي لمحاسبة التتميـة المستدامة وتحسين المحتوي الإعلامي للتقارير المالية "فان الاوساط الحسابي لـه تقع في المدى ما بين (4.05- 4.23) والمنوال (5) والانحراف المعياري يقع في المدى مـا بين (1.07 - 1.28) لجميع العبارات وحسب المقياس الخماسي ليكرت فان إجابات المبحوثين هي موافق وموافق بشدة. 


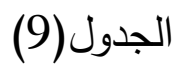

اختبار مربع كاى لعبارات الفرضية الثالثة:

\begin{tabular}{|c|c|c|c|c|c|c|}
\hline الدلاية & الجدئية القــــة & 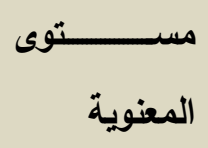 & درجــــة & مريع كاي & |العبارة & p \\
\hline القبول & 4.81 & .000 & 1 & 301.15 & 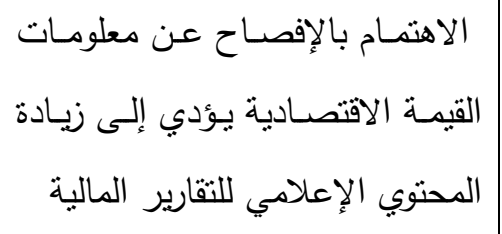 & 1 \\
\hline القبول & 4.13 & .000 & 1 & 315.54 & 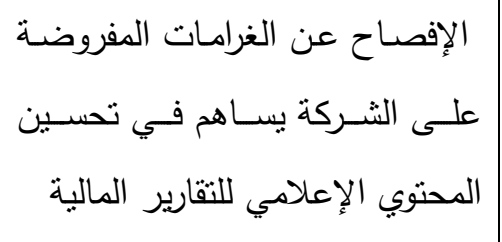 & 2 \\
\hline القبول & 4.31 & .000 & 1 & 431.55 & 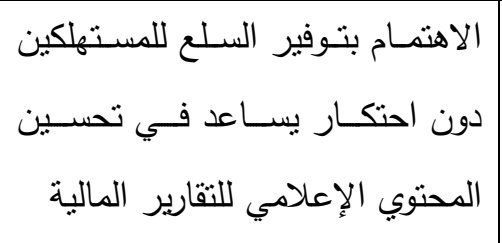 & 3 \\
\hline القبول & 4.79 & .000 & 1 & 376.11 & 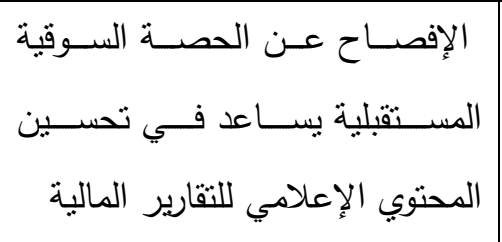 & 4 \\
\hline القبول & 4.02 & .000 & 2 & 323.64 & 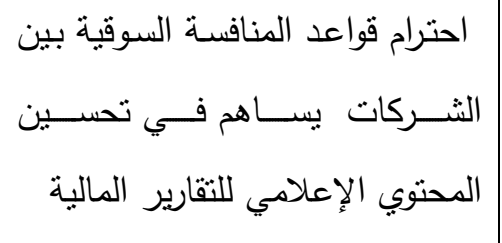 & 5 \\
\hline
\end{tabular}


دور المحاسبة عن التنمية المستدامة في تحسين المتوى الإعلامي للتقارير المالية- ـ د. آدم الطيب حماد حامد

\begin{tabular}{|c|c|c|c|c|c|c|}
\hline القبول & 4.08 & .000 & 1 & 354.21 & 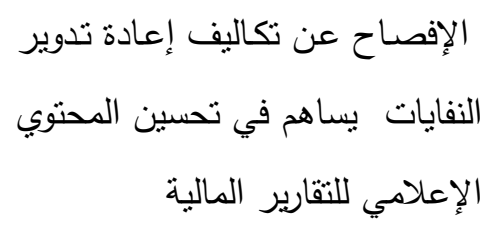 & 6 \\
\hline القبول & 4.51 & .000 & 1 & 294.46 & 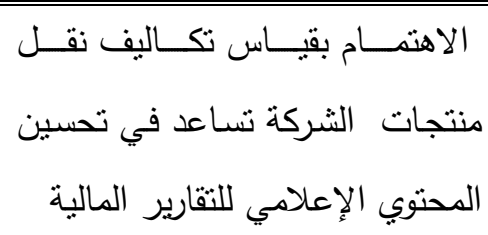 & 77 \\
\hline القبول & 4.29 & .000 & 1 & 318.64 & 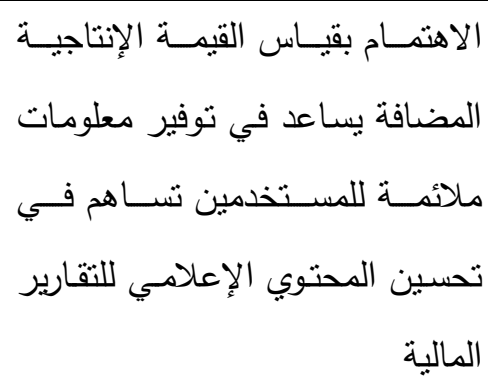 & 8 \\
\hline القبول & 4.19 & .000 & $\overline{1} 1$ & 442.14 & الإلفحساح عن المستوي العام للرواتب & 9 \\
\hline القبول & 4.99 & .000 & 1 & 346.46 & 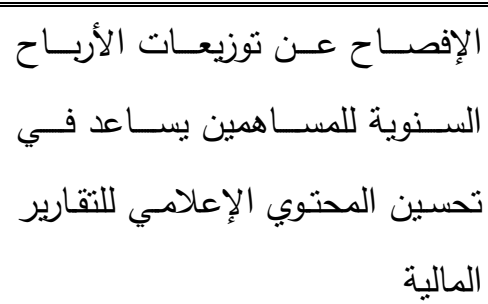 & 10 \\
\hline
\end{tabular}

المصدر : إعداد الباحث، من الدراسة الميدانية، 2020م

يتضح من خلال الجدول (9)لاختبار صحة الفرضية التي تتص على:" توجد علاقة ذات دلالة إحصائية بين الالتزام بالبعـد الاقتصـادي لمحاسبة التتميـة المستـامة وتحسين المحتوي الإعلامسي للتقارير الماليـة "تم استخدام اختبار مربع كاي لعبارات الفرضية وجاءت قيم مربع كاي المحسوبة (301.15 - 315.54 $(346.46$ - 442.14 - 318.64 - 294.46 - 354.21 - 323.64 - 376.11 - 431.55 وبدرجة حرية (1 - 2) والقيمة الجدولية تقع في المدى ما بين (4.02 - 4.99) وبمستوى دلالة Sig لجميع 
العبارات (000.) وعند مقارنـة مستوى الدلالـة sig بمستوى المعنويـة المسموح بـه (0.05) نجد أن مستوى الدلالة sig تقل عن مستوى المعنوية مما يعني وجود فروق ذات دلالة إحصائية لعبارات.

ثالثاً:اختبار الفرضيات: وفيما يلي ملخص لنتائج التحليل الإحصائي الوصفي لجميع فرضيات الدراسة. الجدول (10) (10)

ملخص نتائج التحليل الإحصائي الوصفي لفرضيات الدراسة:

\begin{tabular}{|c|c|c|c|c|c|c|c|c|}
\hline النتيجة & المسنوية & مريع كاي & الموافقة & النسبية & المتوسط & الالمعراف & فرضيات & م \\
\hline قبول & 0.000 & 462.52 & عالية جداً & $\% 86.2$ & 4.31 & 1.22 & الفرضية الاولى & 1 \\
\hline قبول & 0.000 & 378.77 & عالية جداً & $\% 81.8$ & 4.09 & 1.34 & الفرضية الثانية & 2 \\
\hline قبول & 0.000 & 369.11 & عالية جداً & $\% 85.2$ & 4.26 & 1.21 & الفرضية الثالثة & 3 \\
\hline
\end{tabular}

المصدر : إعداد الباحث من بيانات الدراسة الميدانية، 2020م.

يلاحظ من الجدول (10)الذي يوضح ملخص نتائج التحليل الوصفي لفرضيات الدراسة، الفرضية الأولى التي تتص على " توجد علاقة ذات دلالة إحصائية بين الالتزام بالبعد الاجتماعي لمحاسبة التتمية المستدامة وتحسين المحتوي الإعلامي للتقارير المالية " نجد أن أغلبية المبحوثين يوافقون على جميع عبارات الفرضية الأولى وذلك من خلال الوسط الحسابي لجميع العبارات حيث نجد انه اكبر من الوسط

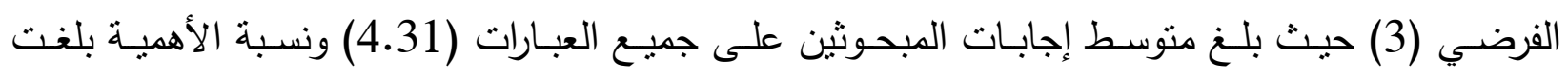
(86.2\%) وقيمـة مربع كاي (462.52) ومستوى المعنويـة (0.000) وذلك يدل على وجود فروقات ذات دلالة إحصائية مما يؤكد أن فرضية الدراسة الأولى قد تحققت. الفرضية الثانيـة: التي تنص على " توجد علاقة ذات دلالـة إحصائية بين الالتزام بالبعد البيئي لمحاسبة التتمية المستدامة وتحسين المحتوي الإعلامي للتقارير المالية" نجد أن أغلبية المبحوثين بوافقون على جميع عبارات الفرضية الثانية وذلك من خـلال الوسط الحسابي لجميع العبارات حيث نجد انه اكبر من الوسط 
الفرضـي (3) حيث بلـغ منوسط إجابـات المبحوثين على جميع العبـارات (4.09) ونسبة الأهميـة بلغتت (81.8\%) وقيمة مربع كاي (378.77) ومستوى المعنوية (000) وذلك يدل على وجود فروقات ذات دلالة إحصائية مما يؤكد أن فرضية الدراسة الأولى قد تحققت. الفرضية الثالثة: التي تتص على " نوجد علاقة ذات دلالة إحصائية بين الالتزام بالبعد الاقتصادي لمحاسبة التتمية المستدامة وتحسين المحتوي الإعلامي للتقارير المالية " نجد أن أغلبية المبحوثين يوافقون على جميع عبارات الفرضية الثالثة وذلك من خـلال الوسط الحسابي لجميع العبارات حيث نجد انه اكبر من الوسط الفرضـي (3) حيـث بلـغ منوسـ إجابـات المبحوثين على جميـع العبـارات (4.26) ونسبة الأهميـة بلغت (85.2\%) وقيمـة مربع كاي (369.11) ومستوى المعنويـة (0.000) وذلك يدل على وجود فروقات ذات دلالة إحصائية مما يؤكد أن فرضية الدراسة الأولى قد تحققت.

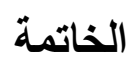
أولاً:النتائج:: 1. أثتبت الدراسة وجود علاقة ذات دلالة إحصائية بين الالتزام بالبعد الاجتماعي لمحاسبة التتمية المستدامة وتحسين المحتوي الإعلامي للتقارير المالية. 2. أثتبت الدراسة وجود علاقة ذات دلالة إحصائية بين الالتزام بالبعد الاجتماعي لمحاسبة التتمية المستدامة وتحسين المحتوي الإعلامي للتقارير المالية. 3. أثنتـت الدراسـة وجود علاقة ذات دلالـة إحصـائية بين الالتزام بالبعد البيئي لمحاسبة التتميـة المستدامة وتحسين المحتوي الإعلامي للنقارير المالية. 4. سـاهم الإفصـاح عن العمل على تحقيق الرفاهيـة الاجتماعيـة للعاملين في تحسين المحتوي الإعلامي للتقارير المالية. 5. ساعد الإفصاح عن البيئة الصحية للعاملين بالثركة في تحسين المحتوي الإعلامي للتقارير المالية. 6. ساعد الاهتمام بتوفير أجهزة لتقليل التلوث البيئي في تحسين المحتوي الإعلامي للتقارير المالية. 7. أدى الاهتمام بالإفصاح عن معلومات القيمة الاقتصادية إلى زيادة المحتوي الإعلامي للتقارير المالية. 8. أدى الإفصـاح عن مشـاريع تتميـة المجتـع بالتقـارير الماليـة إلى تحسين المحتوي الإعلامسي للتقـارير 
ثانياً:التوصيات: أوصت الدراسة بعدد من التوصيات منها: 1. ضرورة الإفصاح عن المعلومات المتعلقة بالبعد البيئي والاجتماعي بالتقارير المالية. 2. ضرورة لالتزام بالبعد الاقتصادي لمحاسبة التتمية المستدامة لتحسين المحتوي الإعلامي للتقارير المالية. 3. العمل على الاهتمام بقياس تكاليف نقل منتجات الثركة لتساعد في تحسين المحتوي الإعلامي للتقارير

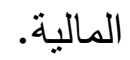

4. ضرورة الاهتمام بقياس القيمة الإنتاجية المضافة ليساعد في توفير معلومات ملائمة للمستخدمين. 5. ضرورة الإفصاح عن المستوي العام للرواتب المدفوعة يساعد في تحسين المحتوي الإعلامي للتقارير. 6. ضرورة الثفافية في الإفصاح عن توزيعات الأرباح السنوية للمساهين لبساعد في تحسين المحتوي الإعلامي للتقارير المالية.

المصادر والمراجع

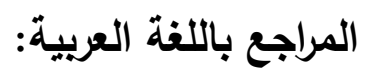

1. احمد بسيوني ومحمد عباس بدوي، المحاسبة الماليـة المتقدمـة، (الإسكندرية: الدار الجامعيـة،

. 2006

2. احمد،خالد محمد، (2014م)، أثر تدريب العاملين بالريف في عملية التنمية الريفية المستدامة،

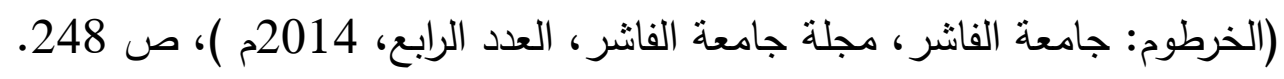
3. الآمين، وليد محمد محمود، (2018))، دور تقارير محاسبة الإستدامة في تحقيق شفافية الآداء

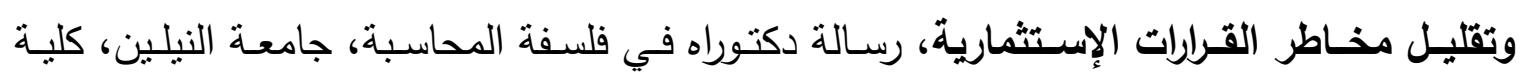

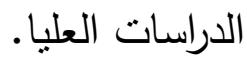

4. دجلة،عبدالحسين،(2014م)، ملامـح الإطار المفاهيمي للمحاسبة عن المسؤولية الاجتماعية في الوحدات الاقتصـادية العراقيـة، (بغداد: جامعـة بغداد، كلية الإدارة والاقتصـاد، رسـالة دكتوراه في الإطي

$$
\text { المحاسبة غير منشورة). }
$$

5.رحاب قريب الله الأمام، دور محاسبة التنمية المستدامة في ترشيد قرارات الاستثمار، رسالة ماجستير في المحاسبة غير منشورة، جامعة النيلين، كلية الدراسات العليا، 2016. 
6. السيد، هيثم محمد عبد الفتاح، (2017م)، تحسين جـودة المحتـوى الإخبـاري للقـوائم الماليـة

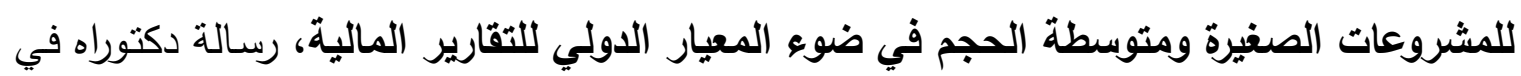
فلسفة المحاسبة، جامعة عين شمس، كلية التجارة.

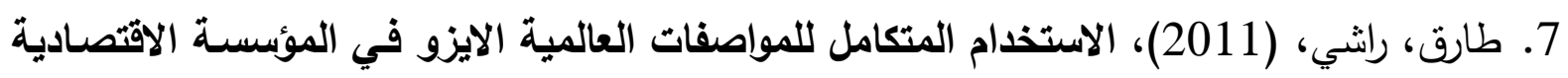

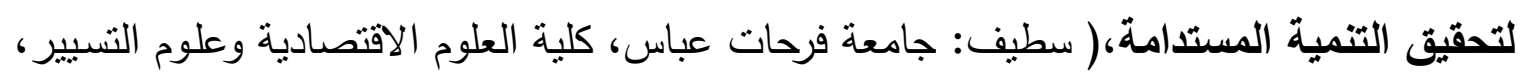
رسالة ماجستير في المحاسبة غير منشورة). 8. طاهر ،جميل،(1997)، الـنفط والتنميـة المسـتامة في الأقطـار العربيـة، (الكويت: مجلـة جسر التتمية، المعهر العربي للتخطيط،).

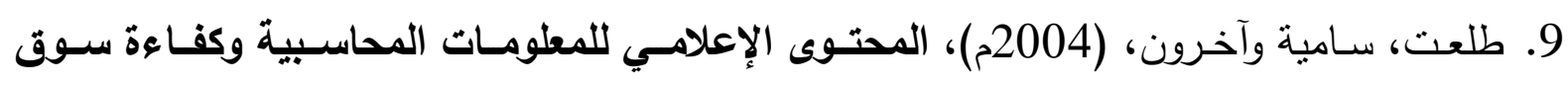

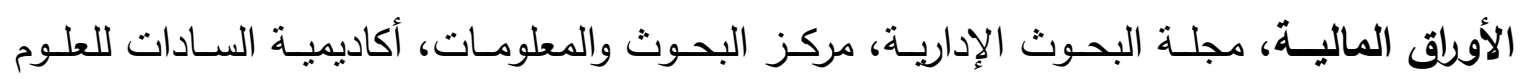

$$
\text { الإدارية، عدد خاص. }
$$

10. عبد الله، عباس عبد الرحمن ادم، (2017)، محاسبة التنمية المستدامة ودورها في تحقيق الميزة التنافسية، دراسة ميدانية على عينه من المنشأت الصناعية بولاية الخرطوم، (الخرطوم: جامعة النيلين ، كلية التجارة، رسالة ماجستير غير منشوره في المحاسبة).

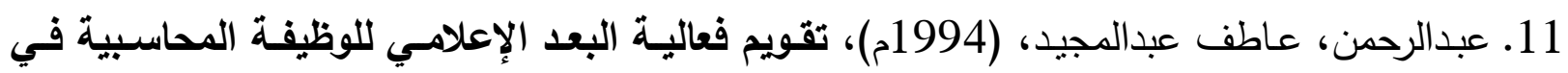

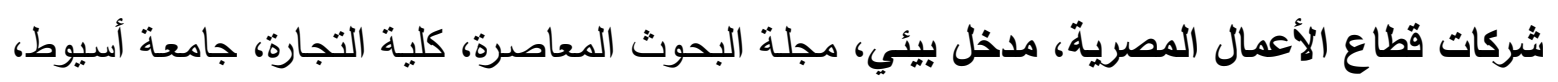

$$
\text { سوهاج، العدد 2، ص صداع الاعمال } 335 .
$$

12. عدلان، محمد الحسن، (2020م)، تقارير الأعمال الموسعة وأثرها في المحتوى الإعلامي للتقارير المالية، رسالة ماجستير في المحاسبة، جامعة آل البيت، كلية الاقتصاد والعلوم الإدارية.

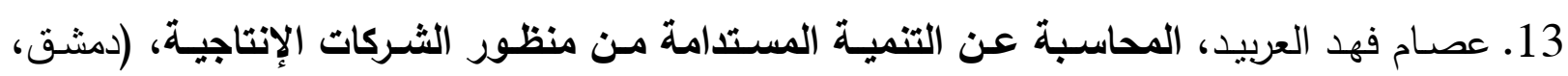

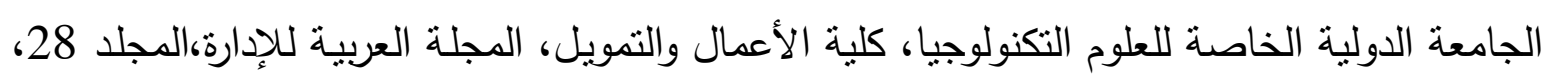
العدد2 2008، 200).

14. عفت أبوبكر محمد الصـاوي، نمـوذج مقترح المحاسـبة عـن تقــارير الإسـتـامة، (القاهرة: جامعـة

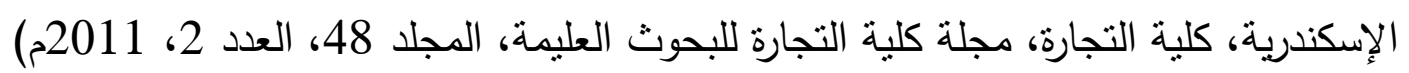

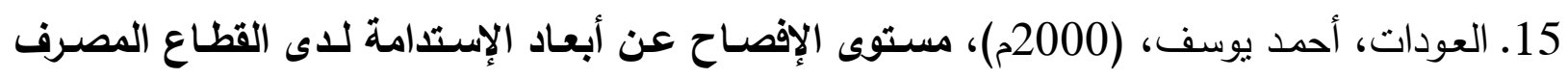
الأردني، رسالة ماجستير في المحاسبة، جامعة آل البيت، كلية الاقتصاد والعلوم الإدارية. 
16. محمد عباس بدوي,المحاسبة في مجال التنمية المستدامة، (القاهرة: جامعة الإسكندرية، كلية التجارة، المكتب الجامعي الحديث، 2013).

17. محمد عباس بدوي، نمـاذج مقترحة لقياس الأداء البيئي والاجتماعي لتقييم إسـهامات المنشـات في

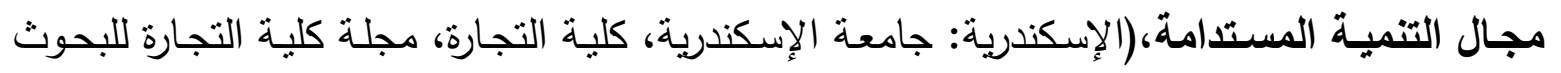
العلمية ، المجلد 48، العدد 2 ، 2011). 18. محمد، عزة، عباس، سامية، (2003م)، اختبار المحتوى الإعلامسي لمكونـات صافي الريح للشركات

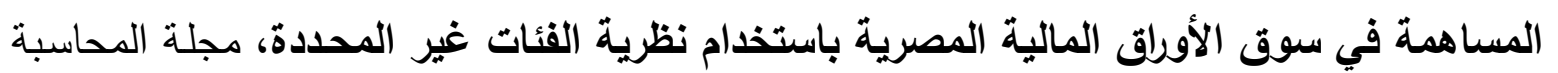
والإدارة والتأمين، كلية التجارة، جامعة القاهرة، العدد 62. 19. مرعي، عبدالحي، (1979م)، نحو فلسفة منطقيـة للتظير المحاسبي، مجلة كلية التجارة للبحوث التجارية، كلية التجارة، جامعة الإسكندرية، العدد الأول.

20. المشهداني، عمر إقبال توفيق، (2016)، دور المحاسبة في المحافظة على البيئة ودعم التنميـة المستدامة، (عمان:جامعة جريش).

21. موسشين، دوجلاس، (2016)، مبادئ التنمية لمستدامة، (القاهرة: الدار الدولية لاستثمارات النقافية).

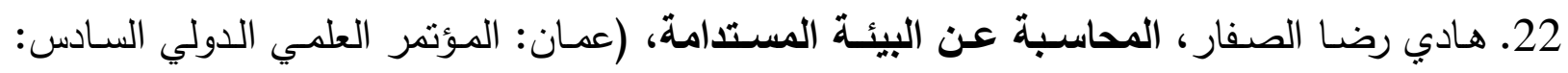

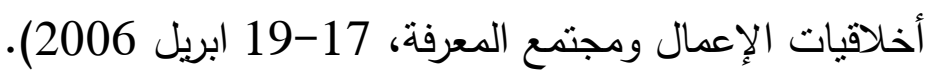

23. يسرى محمد البلتاجي، المحاسبة في مجال التميـة المستدامة، (القاهرة: جامعة الإسكندرية، كلية التجارة، المكتب الجامعي الحديث،2013).

1. Beneda, N.L,(2003),Estimating Free Cash Floes and Valuing A Growth Company, Journal of Assets Management, p 247- 248.

2. Day, Y.F.S,(1986), “ The use of Annual Reports by UK Investment Analysis" Accounting and Business Research, Autumm, pp 301- 305

3. George Brown, (2005), Quality financial reporting, 01 March,

4. http://www.acca.org.uk/publications/studentaccountant/63928. 